Universidad de Lima

Facultad de Comunicación

Carrera de Psicología

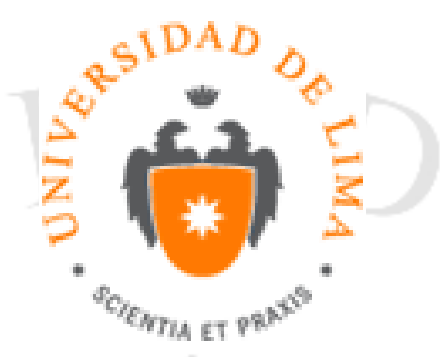

\title{
SÍNDROME DE BURNOUT EN CONDUCTORES DE UNA EMPRESA DE TAXI DE LIMA METROPOLITANA
}

Tesis para optar por el Título Profesional de Licenciado en Psicología Presentada por

David Hurtado Ramirez

Código 20090555

Asesora

MÓNICA GUISELDA FERNÁNDEZ OTOYA

Lima - Perú

Febrero de 2017 


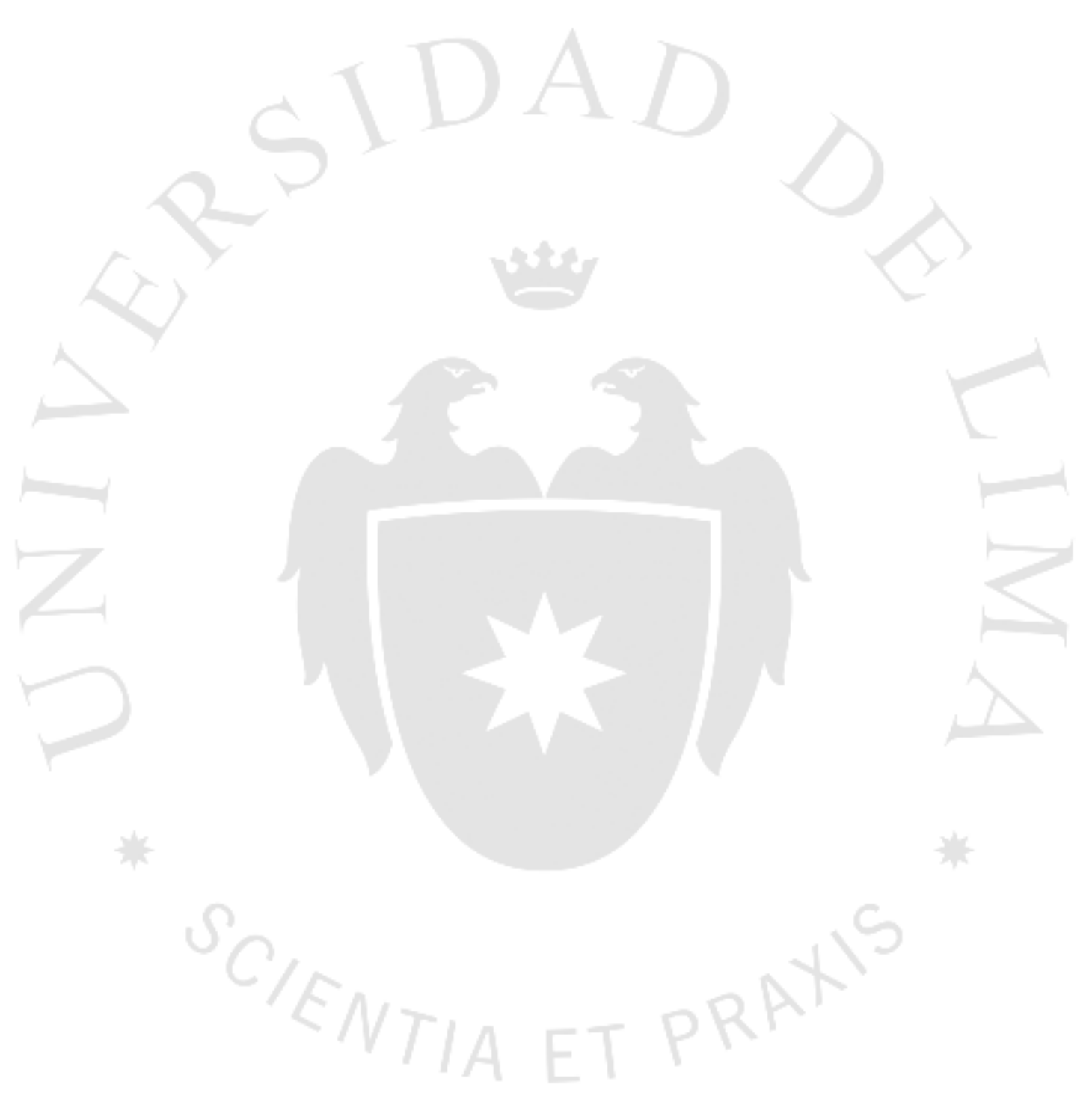




\section{SÍNDROME DE BURNOUT EN TAXISTAS DE UNA EMPRESA DE TAXI DE LIMA METROPOLITANA}




\section{TABLA DE CONTENIDO}

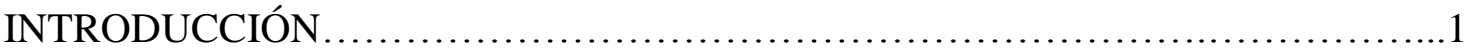

CAPITULO I: PLANTEAMIENTO DEL PROBLEMA ............................................ 2

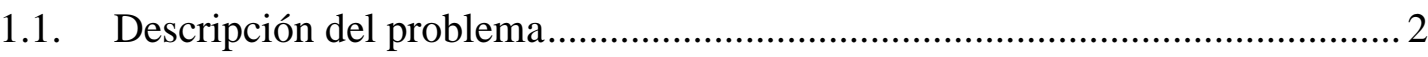

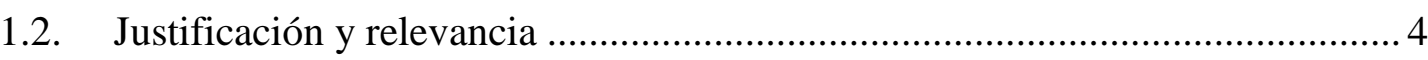

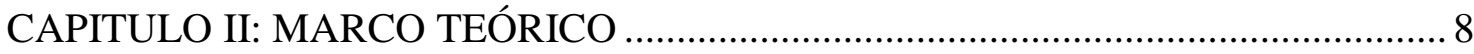

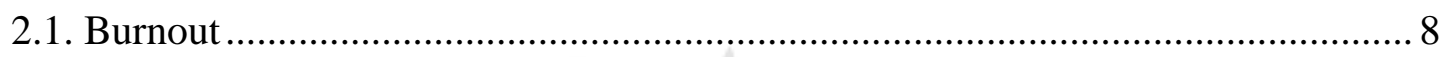

2.1.1. El modelo tridimensional del MBI-HSS................................................ 15

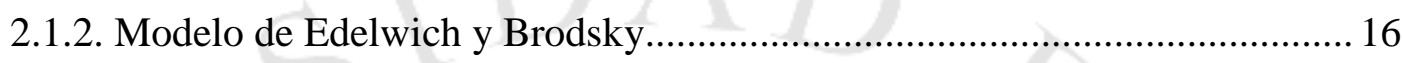

2.1.3. Modelo de Price y Murphy ................................................................. 17

2.1.4. Modelo de las Fases de Burnout de Golembiewski y colaboradores....... 17

2.2. Relación entre Burnout y variables demográficas .............................................. 19

CAPITULO III: OBJETIVOS, HIPÓTESIS Y DEFINICIÓN DE VARIABLES ........ 22

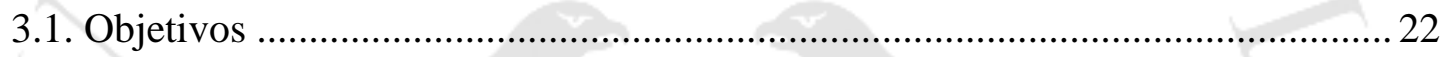

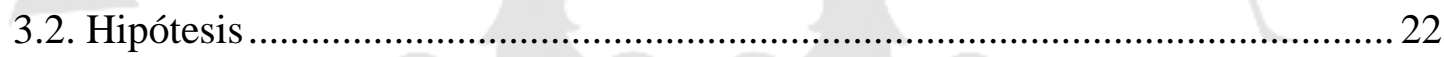

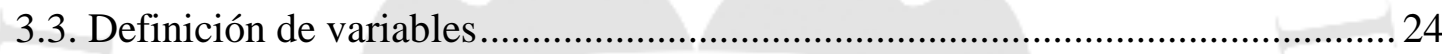

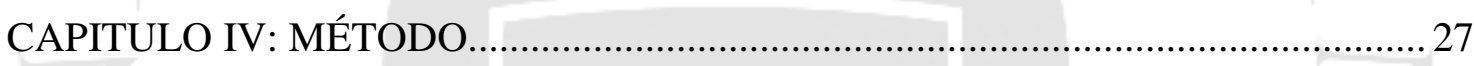

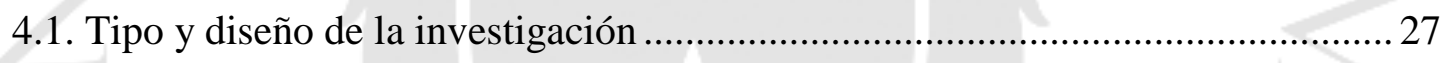

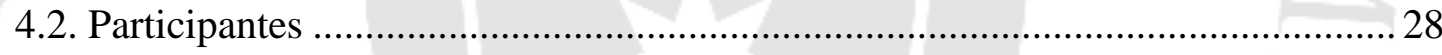

4.3. Técnicas de recolección de información .............................................................. 31

4.3.1. Inventario Burnout de Maslach (MBI) ................................................... 31

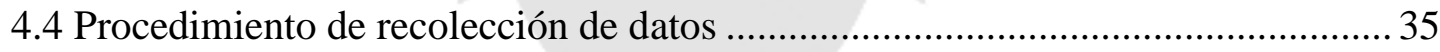

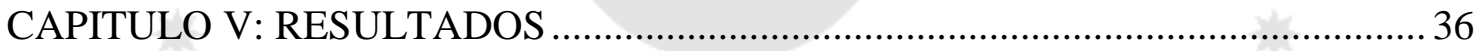

CAPITULO VI: DISCUSIÓN DE RESULTADOS ................................................. 51

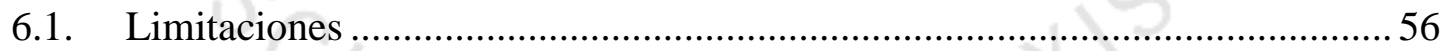

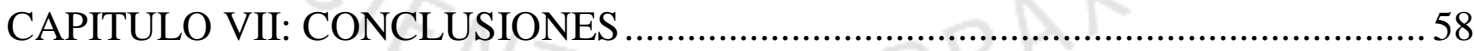

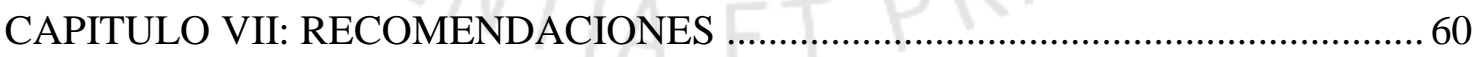

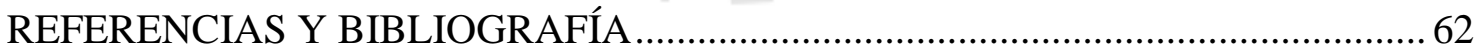

Apéndices

A. Apéndices Instrumentos utilizados

A1. Baremos del Inventario de Burnout de Maslach

A2. Inventario de Burnout de Maslach

A3. Permiso del autor que validó la prueba en el país

B. Cronograma de actividades

C. Presupuesto 


\section{ÍNDICE DE TABLAS}

Tabla 4.1. Distribución de la muestra según edad y según los años que llevan brindando el servicio de taxi, 2015. 29

Tabla 4.2. Clasificación de participantes según su estado civil, 2015. .30

Tabla 4.3. Clasificación de participantes según el nivel de estudios alcanzados, 2015 30

Tabla 4.4. Clasificación de ítems según las dimensiones del Inventario Burnout de Maslach (MBI) .32

Tabla 5.5. Distribución de la muestra según las dimensiones de la prueba, 2015......36

Tabla 5.6. Resultados por dimensiones según percentiles, 2015 .37

Tabla 5.7. Prueba de normalidad de los resultados según estado civil .41

Tabla 5.8. Prueba de normalidad de los resultados según edad .42

Tabla 5.9. Prueba de normalidad de los resultados según nivel de estudio .43

Tabla 5.10. Prueba de normalidad de los resultados según el tiempo de servicio.....44

Tabla 5.11. Prueba de Chi cuadrado para analizar la relación del estado civil con el nivel de agotamiento emocional de la prueba $\mathrm{M}$ 45

Tabla 5.12. Prueba de Chi cuadrado para analizar la relación del estado civil con el nivel de despersonalización de la prueba MBI .46 
Tabla 5.13. Prueba de Chi cuadrado para analizar la relación del estado civil con el nivel de realización personal de la prueba MBI

Tabla 5.14. Porcentaje de agotamiento emocional según estado civil por niveles....47

Tabla 5.15. Coeficiente de correlación de Spearman para medir la relación de la edad con las variables de la prueba MBI .48

Tabla 5.16. Relación entre la dimensión agotamiento emocional y el nivel de estudios. .48

Tabla 5.17. Relación entre la dimensión despersonalización y el nivel de estudios.

Tabla 5.18. Relación entre la dimensión realización personal y el nivel de estudios....

Tabla 5.19. Coeficiente de correlación de Spearman para analizar la relación del tiempo de servicio con las dimensiones de la prueba MBI. 


\section{ÍNDICE DE FIGURAS}

Figura 5.1. Resultados de la dimensión agotamiento emocional por niveles (\%)......38

Figura 5.2. Resultados de la dimensión agotamiento emocional por niveles (\%)......38

Figura 5.3. Resultados de la dimensión despersonalización por niveles (\%)............38

Figura 5.4. Resultados por cantidad de conductores con puntaciones indicadoras de la presencia del síndrome de Burnout en dos o más dimensiones $(\%) \ldots \ldots \ldots \ldots \ldots \ldots . \ldots 40$ 


\section{INTRODUCCIÓN}

La presente investigación busca explorar la salud mental de los conductores de taxis, a fin de conocer la presencia del síndrome de Burnout como también verificar si existen niveles indicadores del síndrome en cada una de sus dimensiones; asimismo, determinar cuál es la asociación de las mismas con variables demográficas como edad, nivel de educación, estado civil y tiempo prestando el servicio de taxi. La investigación se llevó a cabo en una muestra de 232 conductores de taxi de una empresa de Lima Metropolitana. Para explorar la presencia de Burnout se administró el Inventario de Burnout de Maslach (Maslach 1997 en Fernández 2002) y para obtener datos demográficos necesarios para la investigación se utilizó una encuesta donde se preguntó por edad, nivel de educación, estado civil y tiempo de servicio. Los resultados encontrados demuestran que no existe la presencia del síndrome de Burnout en la muestra, es decir, ninguna persona de la muestra presenta la configuración: alto agotamiento emocional, alta despersonalización y baja realización personal. Sólo $5.2 \%$ de la muestra presentan niveles altos de agotamiento emocional, $11.6 \%$ niveles altos en la dimensión despersonalización y $18.1 \%$ niveles bajos de realización personal. Asimismo se encontraron relaciones significativas entre los niveles de agotamiento emocional y estado civil; entre la edad y los niveles de agotamiento emocional, despersonalización y realización personal. Se discute el impacto de los resultados en la relación conductor - pasajero pese a las condiciones ambientales en las que trabajan, asimismo se exploran las relaciones estadísticamente significativas existentes entre las variables sociodemográficas de la muestra y los niveles encontrados de cada una de las dimensiones de Burnout. 


\section{CAPITULO I: PLANTEAMIENTO DEL PROBLEMA}

\subsection{Descripción del problema}

Lima Metropolitana es una ciudad que se caracteriza por concentrar el mayor porcentaje de población de todos los departamentos del Perú. La población estimada de Perú al año 2015 es de 31 millones, 151 mil 643 personas, de las cuales 9 millones 838 mil 251 personas, viven en el departamento de Lima (INEI, 2015). Lima ocupa el $2,7 \%$ del campo geográfico del Perú, y en este pequeño espacio vive aproximadamente el $31 \%$ de la población total.

Este reducido espacio, las limitadas oportunidades laborales y la predisposición a trabajar de manera informal han generado la existencia de un gran número de taxistas, trabajo que se presenta como una alternativa de empleo que solo requiere cumplir con los requerimientos establecidos por la ley y contar un automóvil.

En cuanto al número de conductores de taxi en Lima, hasta el año 2012 existía un parque automotor pequeño y mediano (automóviles, station wagon y distintos tipos de camionetas), de un total de 1,227,535 vehiculos. De este número más de 200,000 vehículos estaban destinados al servicio de taxi (Ministerio de Transportes y Comunicaciones, 2012). Es decir, existen por lo menos dicha cantidad de personas radicadas en Lima dedicadas a prestar al servicio de taxi. 
El conductor de taxi de Lima está acostumbrado a manejar en uno de los lugares más peligrosos para conducir en el mundo (OMS, 2013). A partir de esta información la presente investigación empieza a interesarse por el bienestar mental de los conductores y su impacto sobre el bienestar de los pasajeros.

El tráfico limeño y otras condiciones ambientales adversas, que caracterizan el trabajo del conductor de taxi, hacen difícil que tanto el pasajero como el conductor, puedan mantener un estado emocional inalterable; no obstante, el pasajero solo está expuesto a este ambiente durante algunos minutos de su día, mientras que el conductor es quien está sometido al mismo por varias horas en un día de trabajo.

Esta constante interacción entre pasajero y conductor acompañada de variables como el tráfico y la inseguridad ciudadana se traduce en la sospecha de que pueda existir un desgaste en la relación conductor - pasajero. Este desgaste podría evidenciarse con el trato displicente, las maniobras temerarias, la alta tasa de siniestralidad, las quejas reiteradas, cobros indebidos, constantes negociaciones y renegociaciones, entre otras.

Debido a la presencia de estas características en la relación conductorpasajero, es que se desprende el interés por explorar y/o descartar la presencia o ausencia del síndrome de Burnout en la población de taxistas de Lima. Según Maslach el Burnout es un agotamiento emocional que lleva a la pérdida de la motivación, generando sentimientos de inadecuación y fracaso. El Burnout se manifiesta por tres síntomas o dimensiones: el alto agotamiento emocional, la alta despersonalización y la baja realización personal (Maslach \& Jackson, 1993). 
Este es un síndrome propio de personas que trabajan en contacto directo con otras personas, por lo que la población de taxistas se incluye dentro del perfil. Adicionalmente, varios estudios han demostrado que ciertas condiciones de vida están asociadas con menores o mayores niveles de Burnout (Juárez-García, Idrovo, Camacho-Avila, \& Plasencia-Reyes, 2014). Por lo mismo el presente estudio también se cuestiona si ciertos aspectos de la vida del taxista se relacionan positiva o negativamente con la presencia del mismo, estas variables son: su estado civil, su edad, el nivel académico alcanzado y el tiempo que lleva trabajando como conductor de taxi.

A raíz de lo descrito anteriormente, la presente investigación llega a las preguntas: ¿Existe la configuración del síndrome de Burnout en los conductores de taxi de una empresa de Lima Metropolitana? ¿Cuáles son los niveles de cada una de las dimensiones de Burnout, que presentan los conductores de taxi de una empresa de Lima metropolitana? y ¿Qué relación existe entre las dimensiones del Síndrome de Burnout y las variables sociodemográficas propias de la vida de cada taxista?

\subsection{Justificación y relevancia}

El presente trabajo de investigación busca aportar conocimientos relacionados al Síndrome de Burnout. Síndrome identificado como un fenómeno en expansión y considerado como un riesgo psicosocial. (Gil-Monte, 2011).

A nivel teórico, los conocimientos aquí encontrados permitirán contribuir al marco teórico actual de Burnout ya que se busca despertar el interés de investigar a mayor profundidad a la población elegida. Impulsando y desarrollando ideas y futuras 
hipótesis que tengan como foco "optimizar" la relación de servicio entre los conductores que prestan el servicio de taxi y sus pasajeros.

A nivel metodológico se podrá comprobar y verificar el comportamiento de algunas dimensiones del síndrome con relación a variables sociodemográficas de la muestra. Se puede contribuir al concepto del síndrome en la población de conductores de taxi, así como acercar la metodología y forma de estudiar de una manera más precisa a la población elegida

A nivel práctico, los resultados pueden ser de utilidad para el diagnóstico del estado mental de la población de conductores de taxi en caso se quiera realizar una reforma de transporte en Lima metropolitana.

Los problemas de tránsito tienen un gran costo económico, físico, mental y social. En el Perú, la Oficina General de Defensa Nacional del Ministerio de Salud, ha reportado que entre 1998 y 2008 se produjeron 860102 accidentes de tránsito causando 35596 muertes; Lima fue la región más afectada con 61,73\% de los accidentes; estos constituyen la tercera causa de muerte y su costo anual alcanza los mil millones de dólares, es decir, equivale a un tercio del presupuesto anual destinado a la salud. (Morales-Soto, Alfaro-Basso, \& Gálvez-Rivero, 2010).

Se conoce que en los conductores podrían aparecer algunos rasgos de personalidad o comportamientos que influyen en los accidentes debido al enfrentamiento a situaciones inesperadas y difíciles de resolver como la congestión vial, semáforos inoperativos, retrasos en su rutina, o colisiones. Estos comportamientos tendrían un peso significativo en la propensión a la siniestralidad, algunas de los mencionados son: la impulsividad, inestabilidad emocional, rebeldía, 
tendencia a competir, egocentrismo, inmadurez, inseguridad, tensión y ansiedad (Morales-Soto, Alfaro-Basso y Gálvez-Rivero, 2010).

En la estadística policial un $33 \%$ de accidentes se debió al exceso de velocidad, 28\% a la imprudencia del conductor, $12 \%$ a la imprudencia del peatón, $11 \%$ a conductores en estado de ebriedad y sólo en $6 \%$ se identificó una falla mecánica del equipo o una inadecuada señalización de la vía; en $85 \%$ de casos las causas estuvieron ligadas al hombre, es decir, más del $80 \%$ de los accidentes pudo evitarse con un plan preventivo en favor de trabajar la empatía en base a la concientización que al conducir de manera imprudente se está poniendo en riesgo la vida de una gran cantidad de personas (Policía Nacional del Perú, 2009).

Uno de los principales aportes de esta investigación radica en que se necesita saber si ante fallas humanas, como causas de los accidentes automovilísticos subyacen componentes psicológicos. Conocer esta realidad nos beneficiará para la creación de programas de prevención, que podrán tener una mayor efectividad debido a que se tendrá un mayor conocimiento sobre una posible causa del problema.

Asimismo, conocer la relación entre ciertas variables demográficas que se asocian con la presencia del síndrome, como la edad, la cantidad de años realizando el mismo trabajo, la estabilidad de pareja o la escolaridad (Kirsi, y otros, 2006) (Castillo, Benavente, Arnold, \& Cruz, 2012) (Juárez-García, Idrovo, Camacho-Avila, \& Plasencia-Reyes, 2014) (Ramos, Aldrete, Medina, \& León, 2013) permitirá que el desarrollo de los programas preventivos promuevan ciertas conductas o se aproximen de manera adecuada al grupo más vulnerable.

Finalmente, los resultados que aquí se hallen podrán permitir que el pasajero se sensibilice ante el conductor quien podría estar sometido a grandes cargas de estrés. 
Esta sensibilización permitirá que la relación conductor - pasajero pueda ser más cordial beneficiando a ambos participantes del tráfico limeño. 


\section{CAPITULO II: MARCO TEÓRICO}

\subsection{Burnout}

El Síndrome de Burnout ha resonado en las últimas décadas en el campo psicológico. Sin embargo, para entender a profundidad el concepto es importante primero comprender lo que es el estrés.

El estrés se define, en su forma más básica, como un estado de tensión psicológica creada a partir de una demanda del ambiente (Morris \& Maisto, 2014). La demanda o estímulo que provoca el estrés es entendido como estresor. Por lo tanto, es importante distinguir que el estrés es exclusivamente la reacción fisiológica que pone en marcha el organismo frente a una situación de emergencia, y no el suceso que lo provoca.

Cómo se sabe, el estrés es un agente importante para la sobrevivencia de cualquier especie, si se presenta en la intensidad adecuada puede resultar provechoso. No obstante se vuelve desfavorable cuando se presenta de manera crónica o persiste por periodos de tiempo prolongados (Campillo Álvarez, 2012).

Una de las mayores fuentes de estrés es el trabajo, en éste, la persona se enfrenta a múltiples eventos estresantes como: las demandas que exige su puesto, las 
tareas asignadas, el ambiente de trabajo, etc. Uno de los grandes estresores laborales pueden ser las relaciones interpersonales, es decir el entorno ocupacional donde se desarrolla la persona (Houtman \& Kompier, 2001) y es ahí donde aparece el concepto de Burnout.

El término Burnout se usa por primera vez a mediados de los 70, la traducción al español vendría a ser estar agotado o quemado. Y se crea en base a los niveles de estrés que se observan en trabajos que consisten en ofrecer servicios humanos, es decir, trabajos que involucran el trato humano directo (García Izquierdo, 1993).

Fue el psiquiatra Herbert Freudenberger quien por primera vez utiliza el término en 1974. Él asistía a una clínica para toxicológicos de Nueva York, percatándose que al cabo de un año de trabajo, un gran porcentaje del personal que prestaba sus servicios presentaban ciertos cambios en su actitud hacia el trabajo siendo estos: una progresiva pérdida del energía, desmotivación por el trabajo, trato más distante hacia los pacientes y síntomas característicos de la ansiedad y depresión. Freudenberger denomino a este conjunto de Síntomas Burnout (Bosqued, 2008).

Sin embargo, fue la psicóloga Christina Maslach quien oficializó el término en el Congreso Anual de la APA de 1976. La definición brindada por Maslach sigue siendo la más aceptada a la fecha. Como ya se mencionó en el anterior apartado, la autora propone que el Burnout es un agotamiento emocional que lleva a la pérdida de la motivación, generando sentimientos de inadecuación y fracaso. El Burnout se manifiesta por tres síntomas el alto agotamiento emocional, la alta despersonalización y la baja realización personal. Los tres constructos son detallados con claridad en la descripción del inventario usado en la presente investigación (Maslach \& Jackson, 1993). 
Otras definiciones resaltantes de Burnout que se han dado a lo largo de los años son: "Un proceso en el que las actitudes y las conductas de los profesionales cambian de forma negativa en respuesta al estrés laboral" (Cherniss, 1981). "El estado de agotamiento mental, físico y emocional producido por una persistente implicación en situaciones emocionalmente demandantes" (Pines, Aronson, \& Kafry, 1980).

Asimismo, Gil-Monte (2011) define el Burnout como "Una respuesta al estrés laboral crónico que tiene una gran incidencia en los profesionales del sector servicios que trabajan hacia las personas. Se caracteriza por un deterioro cognitivo, una experiencia de desgaste psicológico y por la aparición de actitudes y conductas negativas hacia los clientes y hacia la organización”.

En cuanto a las causas del Burnout, son distintos estresores externos que acompañan la relación entre colaborador - cliente los que pueden propiciar la aparición del síndrome. José María Prieto (2005), hace una compilación de los estresores que varios autores consideran como generadores de Burnout. Los divide en estresores del ambiente físico, demandas estresantes del trabajo y contenidos del propio trabajo. Estresores del ambiente físico tales como: el ruido, vibraciones, niveles de temperatura inadecuados para trabajar, mala iluminación, pobres condiciones higiénicas, toxicidad y una inadecuada disposición del espacio físico para el trabajo. Demandas estresantes del trabajo como: trabajo por turnos o trabajo nocturno, sobrecarga laboral y exposición a riesgos y peligros. Contenidos propios del trabajo como: poco sentido de control, poca oportunidad para el uso de habilidades, tareas monótonas, poca retroalimentación y funciones poco definidas.

Además de las ya antes mencionadas, otros autores identifican factores organizativos como el contacto continuo con el dolor y las emociones de los demás, falta de medios para realizar las tareas encomendadas, cambios sociales y/o 
tecnológicos continuos a los que hay que adaptarse rápidamente, clima sociolaboral existente en la empresa y el estilo directivo del jefe inmediato (Bosqued, 2008).

En cuanto a los signos y síntomas que presentan las personas que padecen el Síndrome de Burnout, como ya se mencionó, la mayoría de autores concuerdan en la presencia de 3 síntomas principales: un alto nivel de despersonalización, un bajo sentido de realización personal y un elevado agotamiento emocional.

No obstante, dentro de estos síntomas principales se pueden encontrar 4 subtipos de sintomatologías (Bosqued, 2008). Cabe resaltar que cada persona tiene una combinación distinta de los síntomas que se mencionarán a continuación:

1. Síntomas físiológicos o físicos como: cansancio, fatiga crónica, insomnio, tensión muscular, alteraciones en el apetito, migrañas, taquicardia, dificultades para respirar, alteraciones gastrointestinales, entre otras.

2. Síntomas emocionales como: Irritabilidad, sensación de fracaso, ausencia del sentido del humor, baja autoestima, decadencia de la motivación laboral, inseguridad, aislamiento social, baja tolerancia a la frustración, entre otras.

3. Síntomas cognitivos como: problemas de atención, dificultades de memoria, negación del problema, ideación negativa hacia la organización, desinterés en el trabajo, pensamientos acerca del abandono profesional e incluso ideación suicida en los casos más extremos.

4. Síntomas del comportamiento tales como: disminución en el rendimiento laboral, evitación de responsabilidades, aumento del ausentismo laboral, críticas exageradas, conflictividad interpersonal, tendencia a adoptar conductas de riesgo, abuso de sustancias, entre otros 
Las investigaciones acerca del Burnout son diversas y se han aplicado en distintos lugares y con distintas poblaciones. Un estudio interesante es el de Cortés quien lleva a cabo una investigación en la que midió los niveles de Burnout en un grupo de 148 conductores de diversos medios de transporte público de una empresa privada de Colombia (buses interdepartamentales, buses locales y taxistas). La prueba utilizada fue el inventario MBI de Maslach, y se encontró, que en promedio, el grupo de taxistas se encontraba satisfecho con su labor como conductores; no obstante, se detectó la presencia de estrés laboral así como poco interés y actitudes negativas hacia las personas con las que trabajan (Cortés Zábala, 2009).

En otro estudio se midieron los niveles de Burnout en un grupo de 94 conductores de líneas de transporte locales la ciudad de Arequipa, los resultados resultaron preocupantes, se encontró que un $78.7 \%$ de los participantes presentaba un elevado agotamiento emocional, un $88.3 \%$ puntuaba alto en el factor de despersonalización y 37.2\% tiene baja realización en la escala MBI de Maslach. Los autores atribuyen estas puntuaciones a las condiciones en las que trabajan los conductores y a la naturaleza de la ocupación, pues deben pasar varias horas al día haciendo una actividad rutinaria como es conducir; de la misma manera, afirman que estas altas puntuaciones también explican el trato displicente que muchas veces les dan a los pasajeros; así como la poca importancia que le dan a la vida de las personas que llevan en su vehículo, pues constantemente se observan varias maniobras temerarias en el tránsito arequipeño (Arias Gallegos, Mendoza del Solar, \& Masias Salinas, 2013).

Resulta bastante importante la comparación que Arias Gallegos hace tomando como referencia los estudios de Arias y Jimenes (2012). Se comparan los niveles de Burnout encontrados en conductores con la población de enfermeras, maestros y 
policías. Mientras que en su muestra se encuentra un $54,3 \%$ de conductores con la presencia del síndrome de Burnout, se observa que solo un $13 \%$ de enfermeras, $6,6 \%$ de profesores y 53\% policías presentan síntomas severos. Es decir, el grupo laboral de mayor riesgo es el de los conductores.

Otro estudio que permite entender a los conductores de Lima metropolitana es el que fue llevado a cabo por Mallma, Rivera, Rodas y Farro (2013). Se investigaron las condiciones laborales y los comportamientos de salud que los conductores de una empresa de transporte público del cono Norte de Lima. Se encontraron varios elementos desfavorables para la salud mental y física de los conductores: el $26,5 \%$ trabaja más de 12 horas diarias, y están expuestos a agentes físicos como ruido 99,2\% y alérgenos como humo 98,5\%. En relación a comportamientos en salud el $59 \%$ no duerme más de 8 horas al día y el 53,8\% considera que su alimentación no es saludable. Asimismo, el $53 \%$ manifestó que su trabajo les ocasiona tensión emocional. Es importante resaltar que en esta investigación se identifica que las constantes peleas entre pasajero - conductor ocasionan que el conductor tenga estallidos de ira, exteriorizando agotamiento y estrés.

Un estudio en México llega a conclusiones parecidas a las ya mencionadas, se encontró en choferes de transporte público de la ciudad de Chilpancingo que la prevalencia de los niveles de estrés fueron más altos a los esperados, 26.17\%. Se encontraron 12 estresores asociados al hiperestrés, dentro de lo que resaltan las tensiones en el trabajo, ponerse nerviosos con tráfico lento y el insomnio (González Ramírez. et al, 2013).

Otro estudio llevado a cabo en el Perú es el de Salazar y Pereda (2010). Se evaluaron los niveles de Burnout y los patrones de comportamiento en el contexto de 
tráfico en 237 conductores de buses interprovinciales de la ciudad de La libertad. Los resultados indicaron que el síndrome de Burnout no está presente en la mayoría de conductores. Sin embargo los participantes con puntuaciones indicadoras de la presencia del síndrome de Burnout, correlacionaron positivamente con tener un comportamiento impulsivo con escaso control personal y falta de respeto a los demás usuarios y a las normas de tráfico.

También es importante mencionar la investigación de Toppinen-Tanner. et al. (2005) que se ha enfocado en estudiar las consecuencias en la persona con Burnout. Encontraron que la presencia del síndrome incrementa el riesgo del ausentismo en el trabajo ya que ocasiona desórdenes mentales y de comportamiento; enfermedades en el sistema circulatorio, respiratorio, así como problemas en los músculos y huesos. Para el estudio también se utilizó la prueba MBI de Maslach. Las correlaciones que se encontraron entre los distintos constructos de la prueba y enfermedades fisiológicas fueron los siguientes: las personas que puntuaron alto en agotamiento emocional correlacionaron fuertemente con la presencia de enfermedades del sistema circulatorio, mientras que una puntuación alta en "bajo sentido de realización" estaba fuertemente correlacionado con enfermedades del sistema digestivo.

Habiendo hecho una revisión del concepto y la bibliografía a la fecha, es importante también mencionar la creación de modelos teóricos centrados en el síndrome. Algunos de ellos son: 


\subsubsection{El modelo tridimensional del MBI-HSS}

El MBI-HSS es el cuestionario más popular y más utilizado para la evaluación psicométrica del síndrome. El cuestionario está conformado por 22 ítems que se distribuyen en tres dimensiones: los niveles de realización personal en el trabajo, el agotamiento emocional y la despersonalización, que consiste en dejar de ver a las personas como tales, sino como objetos o entes sin emociones que son parte de su trabajo. Puntuaciones bajas en la primera y altas en las otras dos, definen el síndrome (Maslach \& Jackson, 1986). Ya que este modelo es el que se ha tomado en cuenta para la presente investigación, se definirá a profundidad las tres dimensiones y los niveles altos, medios y bajos en el apartado de técnicas de recolección de la información.

Esta teoría se ha desarrollado a partir del análisis factorial de los ítems, análisis que permitió establecer las 3 dimensiones previamente mencionadas, definir el síndrome y sus síntomas.

Desde que se creó el cuestionario en 1982, la teoría y el dinamismo entre las 3 dimensiones ha sido y sigue siendo discutido, distintos autores han otorgado mayor o menor importancia a alguna de las dimensiones o sugieren que una es causa o consecuencia de otras. Tales son los casos de Lee y Ashforth (1993), Gil-Monte (1998), Dougherty y Blum (1997), Berkowitz (1996), entre otros (como se citó en Gil-Monte, 2011).

El modelo más aceptado y con mayores índices de confiabilidad en los estudios que se han llevado a la fecha, es el elaborado por Gil-Monte en el año 1994. Este modelo indica que la despersonalización sucede luego que la persona tenga baja realización personal, tenga un fuerte agotamiento emocional o una mezcla de ambas. 
Los resultados hayan una fuerte relación entre agotamiento emocional y despersonalización pero algunos estudios no encuentran los niveles de significación suficientes para la relación entre baja realización personal en el trabajo y despersonalización (Gil-Monte, 2011).

\subsubsection{Modelo de Edelwich y Brodsky}

Estos autores muestran que el Burnout es un proceso de 4 fases en las que la persona se va cansando o desencantando de la actividad laboral. La primera fase es el entusiasmo y consiste en la etapa en la que la persona inicia su trabajo, desarrolla una gran ilusión, energía e incluso expectativas bastante positivas acerca de lo que vivirá en su trabajo.

En la segunda fase la persona entra en una etapa de "estancamiento". El trabajador ahora centra su atención en otros aspectos de su vida personal. Empieza a otorgarle mayor valor al salario y a los beneficios de su trabajo. La siguiente etapa es la frustración. El individuo empieza a cuestionar su trabajo, no está seguro si vale la pena tanto esfuerzo, empieza a sentirse insatisfecho y aparecen problemas emocionales, fisiológicos y conductuales.

La última fase se denomina apatía, los autores la consideran como un mecanismo de defensa frente a la frustración. La persona solo mantiene su trabajo porque lo necesita para sobrevivir, por lo tanto, hace solo lo mínimo e indispensable para conservar el mismo. Lo único que ahora aprecia del trabajo es la estabilidad laboral (Edelwich \& Brodsky, 1980). 


\subsubsection{Modelo de Price y Murphy}

Los autores de este modelo plantean que el Burnout es un proceso muy similar a un proceso de duelo, donde la persona tiene perdidas a nivel personal, a nivel interpersonal y a nivel social e institucional.

En este modelo se contempla un proceso que pasa por 6 fases sintomáticas. Se empieza por una fase de desorientación, donde el profesional entiende que no alcanza los objetivos con las personas para las que trabaja. En la segunda fase la persona desarrolla una inestabilidad emocional, que se incrementa por el poco apoyo que pueden ofrecerle sus colegas y por el distanciamiento emocional que usan los profesionales de ayuda como estrategia de afrontamiento. En esta etapa la persona no desahoga sus emociones y es ahí donde pasa por periodos de labilidad y desgaste emocional.

La tercera fase se caracteriza porque la persona experimenta sentimientos de culpa debido al fracaso profesional, además se atribuye errores que no dependen de su control, la persona se torna fría y distante. La siguiente fase del proceso es la de soledad y tristeza, cuyo nombre habla por sí misma. Si esta fase se supera pueden ocurrir las dos siguientes: Fase de solicitud de ayuda y fase de restablecimiento del equilibrio inicial con el que se inició en la profesión (Price \& Murphy, 1984).

\subsubsection{Modelo de las fases de Burnout de Golembiewski y colaboradores}

Los autores parten de la concepción de Burnout que ofrece el MBI de Maslach. Sin embargo, postulan que algunas dimensiones del MBI son mejores 
predictoras que otras. Indican que la dimensión que mejor predice la aparición del síndrome es la despersonalización, seguida de la reducida realización personal y finalmente el agotamiento emocional. Asimismo, indican que para conocer a profundidad el síndrome es necesario estudiar los pensamientos del individuo ante los eventos aversivos generadores del síndrome (Golembiewski \& Munzenrider, 1988).

Asimismo, cambian la clasificación de las puntuaciones obtenidas del MBI hecha inicialmente por Maslach (Bajo, Medio y Alto) y la dicotomizan en altas y bajas. Al hacer la combinación de las tres variables ya mencionadas anteriormente, clasificando cada una en alto y bajo, se obtienen ocho configuraciones de Burnout que denominan fases. Las 8 fases se clasifican de la siguiente manera:

Las fases I, II o III implicarían la ausencia del síndrome o, en su defecto, un Burnout leve. Estas fases implican: tener bajas puntuaciones en todas las dimensiones excepto en realización personal que funciona de manera inversa, sólo tener puntuación alta en la dimensión de agotamiento emocional y realización personal o tener una puntuación baja en las tres dimensiones incluyendo la realización personal.

Las fases IV o V implicarían un Burnout medio, es decir tener una puntuación elevada en la dimensión de agotamiento emocional, y baja puntuación en realización personal y despersonalización o tener una puntuación alta en las tres dimensiones.

Finalmente se considera la presencia del síndrome o un Burnout elevado si tiene puntuaciones propias de las fases VII u VIII. Que comprenderían las siguientes configuraciones: puntuación alta de despersonalización y baja puntuación en agotamiento emocional y realización personal o alta puntuación en despersonalización y agotamiento emocional y baja puntuación en realización personal. 


\subsection{Relación entre Burnout y variables demográficas}

En cuanto a la asociación de la presencia del síndrome de Burnout con datos demográficos, se ha encontrado resultados muy variables.

Un estudio realizó una búsqueda en 12 bases de datos considerando las que incluyen revistas latinoamericanas. Se examinaron todos los artículos existentes hasta el mes de julio de 2012. Se realizaron metaanálisis en los promedios de las dimensiones de Burnout con distintas variables, entre ellas variables demográficas (Juárez-García, Idrovo, Camacho-Avila, \& Plasencia-Reyes, 2014).

Con respecto a estas variables se destaca la edad como una de las variables más frecuentemente señaladas (20.31\%), el sexo (20.31\%), la antigüedad (17.18\%), el estado civil o estabilidad de pareja (14.06\%) y la escolaridad (12.50\%). En cuanto a las variables laborales, la jornada o número de horas de trabajo (7.8\%), la sobrecarga de trabajo (6.25\%), las condiciones físicas en que se realiza el trabajo (6.25\%), la posibilidad de interacción social $(6.25 \%)$, el contenido o naturaleza del trabajo (4.68\%), el puesto (4.68\%), los sistemas de trabajo (4.68\%) entre otros. Asimismo se encontraron el número de hijos $(3.12 \%)$, la relación con la pareja $(3.12 \%)$ o las exigencias del hogar $(3.12 \%)$.

Se realizó un estudio transversal, analítico en una institución pública de atención primaria en Guadalajara, México. Se aplicó la prueba MBI en los 279 trabajadores de la institución. Los resultados arrojaron lo siguiente: en cuanto a los factores de riesgo para desarrollar síndrome de Burnout; el agotamiento emocional se asoció significativamente con la edad; se identificó al grupo de más de 48 años de edad como el grupo de mayor riesgo para desarrollar este trastorno. La 
despersonalización se asoció de manera significativa con la edad y con la antigüedad laboral; se encontró que los dos grupos con mayor número de años presentaron mayor riesgo de presentar esta dimensión alterada. Asimismo, el grupo con menor número de años laborados en la institución (1 a 8 años) tuvieron mayor riesgo de sufrir de despersonalización. En cuanto a la falta de realización personal los principales factores de riesgo fueron la escolaridad. Mientras menores fueron los niveles de escolaridad alcanzados mayor fue la presencia de baja realización personal (Ramos, Aldrete, Medina, \& León, 2013).

Por otro lado, Kirsi señala que no hay evidencia suficiente para señalar un rango de edad cómo factor de riesgo. No obstante, un bajo nivel de educación y pertenecer a un nivel socioeconómico bajo genera un posible riesgo en mujeres, mientras que estar solo, divorciado o viudo genera un posible riesgo a tener el síndrome en los hombres (Kirsi, y otros, 2006).

Otro estudio investigó la asociación de variables demográficas con los niveles de Burnout de los trabajadores de un hospital chileno. No hubo asociación estadística entre síndrome de Burnout y las variables: sexo, edad, áreas de servicios, horas de trabajo, número de turnos noche y estado civil. Por otro lado, sí hubo asociación con las variables número de hijos y profesión. La asociación encontrada indica que los trabajadores con hijos presentaban menores niveles de Burnout que su contraparte (Castillo, Benavente, Arnold, \& Cruz, 2012).

En resumen, hay una vasta bibliografía sobre el tema; sin embargo, solo se encontraron dos investigaciones que investigan la presencia del síndrome en conductores que prestan el servicio de taxi. El modelo de Maslach es el más aceptado a la fecha y también es el elegido para la presente investigación. Finalmente, son numerosas las variables que pueden tener una relación significativa con la presencia 
del síndrome. Las variables tomadas en cuenta para la presente, han sido elegidas debido a que tienen un antecedente de relación significativa en los estudios previamente mencionados y por criterio del investigador. 


\section{CAPITULO III: OBJETIVOS, HIPÓTESIS Y DEFINICIÓN DE}

\section{VARIABLES}

\subsection{Objetivos}

- Identificar y describir la presencia o ausencia del síndrome de burnout en conductores de una empresa de taxi de Lima metropolitana.

- Describir las dimensiones de Burnout observadas en los conductores de una empresa de taxi de Lima Metropolitana.

- Identificar relaciones entre las dimensiones de Burnout observadas en conductores de una empresa de taxi de Lima Metropolitana con las variables: estado civil, nivel de estudios, edad y tiempo de servicio.

\subsection{Hipótesis}

- Un porcentaje significativo de conductores de una empresa de taxi de Lima metropolitana presentan la configuración que indica la presencia del síndrome (alto nivel agotamiento emocional y despersonalización y bajo nivel de realización personal). 
- Los conductores de una empresa de taxi de Lima metropolitana presentan puntuaciones altas en agotamiento emocional, altas en despersonalización o bajas en realización personal

- Existe relación estadísticamente significativa entre los niveles de agotamiento emocional y el estado civil de los conductores de una empresa de taxi de Lima metropolitana.

- Existe relación estadísticamente significativa entre los niveles de agotamiento emocional y el nivel de estudios alcanzado de los conductores de una empresa de taxi de Lima metropolitana.

- Existe relación estadísticamente significativa entre los niveles de agotamiento emocional y la edad de los conductores de una empresa de taxi de Lima metropolitana.

- Existe relación estadísticamente significativa entre los niveles de agotamiento emocional y el tiempo de servicio de los conductores de una empresa de taxi de Lima metropolitana.

- Existe relación estadísticamente significativa entre los niveles de despersonalización y el estado civil de los conductores de una empresa de taxi de Lima metropolitana.

- Existe relación estadísticamente significativa entre niveles de despersonalización y el nivel de estudios alcanzado de los conductores de una empresa de taxi de Lima metropolitana.

- Existe relación significativa entre niveles de despersonalización y la edad de los conductores de una empresa de taxi de Lima metropolitana. 
- Existe relación significativa entre niveles de despersonalización y el tiempo de servicio los conductores de una empresa de taxi de Lima metropolitana.

- Existe relación significativa entre los niveles de realización personal y el estado civil de los conductores de una empresa de taxi de Lima metropolitana.

- Existe relación significativa entre niveles de realización personal y el nivel de estudios alcanzado de los conductores de una empresa de taxi de Lima metropolitana.

- Existe relación significativa entre niveles de realización personal y la edad de los conductores de una empresa de taxi de Lima metropolitana.

- Existe relación significativa entre niveles de realización personal y el tiempo de servicio de los conductores de una empresa de taxi de Lima metropolitana.

\subsection{Definición de variables}

La variable considerada para este estudio es el Burnout y, por consiguiente, sus dimensiones: Agotamiento emocional, Despersonalización y Realización personal. Para definir cada una de las variables se ha tomado como referencia a los autores de la prueba MBI que será utilizada para esta investigación. Conceptualmente definen el Burnout como un agotamiento emocional que lleva a la pérdida de la motivación, generando sentimientos de inadecuación y fracaso. Este se manifiesta por tres síntomas; el agotamiento emocional, la despersonalización y la falta de realización personal. Operacionalmente el síndrome se define por altas puntuaciones en agotamiento emocional y despersonalización y baja puntuación en realización personal. (Maslach \& Jackson, 1993). En cuanto las dimensiones, estas se definen de la siguiente manera: 
Agotamiento emocional: La fuerza o capital emocional del trabajador se va consumiendo y su capacidad de entrega hacia los demás se vacía tanto a nivel personal como psicológico. Operacionalmente será considerada como la puntuación total de la dimensión “Agotamiento emocional” en el Inventario Burnout de Maslach (MBI). Puntuación que se obtiene con la suma de las puntuaciones indicadas en los elementos 1, 2, 3, 6, 8, 13, 14, 16, 20.

Despersonalización: La aparición de sentimientos y/o actitudes negativas y cínicas acerca del sujeto con el que trabaja. Operacionalmente será considerada como la puntuación total de la dimensión "Despersonalización” en el Inventario Burnout de Maslach (MBI). Puntuación que se obtiene con la suma de las puntuaciones indicadas en los elementos $5,10,11,15,22$.

Falta de realización personal: La tendencia de evaluarse negativamente, surge de modo especial cuando el profesional trabaja con personas. Operacionalmente será considerada como la puntuación total de la dimensión "Realización personal" en el Inventario Burnout de Maslach (MBI). Puntuación que se obtiene con la suma de las puntuaciones indicadas en los elementos 4, 7, 9, 12, 17, 18, 19, 21.

En lo que respecta las variables demográficas se entienden de la siguiente manera:

Edad: Número de años de vida cumplidos por el conductor desde su fecha de nacimiento hasta el día en que se realizó la prueba

Estado civil: Condición del conductor según el registro civil en función de si tiene o no pareja y su situación legal respecto a esto. 
Nivel de estudios alcanzado: Máximo nivel académico obtenido por los conductores de acuerdo a la institución y tiempo estudiado en las mismas.

Tiempo de servicio: Número de años que el conductor ha acumulado brindando el servicio de taxi. 


\section{CAPITULO IV: MÉTODO}

\subsection{Tipo y diseño de la investigación}

La presente investigación tiene un diseño cuantitativo no experimental, de método descriptivo. Las variables no son manipuladas debido a que se espera que el fenómeno pueda presentarse en el contexto natural donde se desenvuelve la población elegida y su principal objetivo es describir a profundidad. Se medirán los niveles de cada una de las dimensiones de Burnout, se describirán los resultados y se relacionarán con los datos demográficos de edad, tiempo de servicio, estado civil y tiempo de servicio. Asimismo, se trata de una investigación transeccional porque las variables se medirán en un único momento para determinar su nivel en la muestra. (Hernández, Fernández, \& Baptista, 2014).

Se optó por este tipo y diseño de investigación, porque el constructo seleccionado puede ser medido a través de una prueba psicométrica. Asimismo la metodología se debe a que el autor de esta investigación considera que de acuerdo a la bibliografía encontrada a la fecha, es necesario llevar a cabo más investigaciones que describan la presencia o ausencia del síndrome en la población en mención. 


\subsection{Participantes}

El grupo de participantes estuvo compuesto por personas que se dedican a realizar el servicio de taxi en una empresa de taxi de Lima metropolitana. El total de conductores afiliados a la empresa fue de aproximadamente 2,000 conductores al año 2015, año en que se tomó el muestreo.

Considerando las sugerencias metodológicas según el tipo de estudio y teniendo en cuenta que no existen estudios previos, se asumió la correlación mínima de .25 (Cohen, 1988). Se procedió a utilizar el programa estadístico G.Power 3.1 (Buchner, Erdfelder, Faul y Lang, 2014) y se obtuvo una muestra mínima de 232 conductores. Además, se utilizó un nivel de significancia de $p=.05$, y el valor de la potencia seleccionada (.85) supera el estándar mínimo recomendado de .80 (Wright, 2003).

El muestreo realizado es no probabilístico, seleccionado de manera intencionada y por conveniencia, ya que los participantes son previamente identificados para que cumplan con las características que se buscan. Se incluyeron a todos los conductores que se acercaron a recibir capacitaciones en un periodo de tres semanas.

Se tienen en cuenta ciertos criterios de exclusión que podrían reducir la población (Hernández, Fernández, \& Baptista, 2014).

- No se tomaron en cuenta a las conductoras de sexo femenino, esto debido a que la cantidad de conductoras es menor al de conductores de sexo masculino, aproximadamente 1 mujer por cada 40 hombres, por lo que no se podrían tener resultados significativos teniendo en cuenta 
que el acceso que se tuvo a la población fue de máximo 20 conductores por día laboral durante 15 días.

- Se excluyeron todos los conductores que no llenaron el apartado de datos demográficos o que no siguieron las instrucciones de la prueba.

Como se observa en la tabla 4.1 todos los participantes son de sexo masculino con un rango de edad de 21 a 66 años y una edad media de 37 años. Asimismo llevaban realizando el servicio de taxi en un rango que va desde los 0 hasta los 30 años, siendo 5 años el promedio.

Tabla 4.1

Distribución de la muestra según edad y según los años de servicio, 2015

\begin{tabular}{l|cccc}
\hline & Mínimo & Máximo & Media & Desviación \\
& & & & estándar \\
\hline Edad & 21 & 66 & 37.2 & 8.8 \\
\hline Tiempo de servicio & 0 & 30 & 5.2 & 5.2 \\
\hline (años) & & & \\
\hline
\end{tabular}

Nota: Total de taxistas evaluados (232).

En cuanto al estado Civil de los participantes, se observa en la tabla 4.2, que 72 son solteros (31\%), 118 son casados $(50,9 \%), 9$ son divorciados $(3,9 \%)$ y 33 clasifican su estado civil como otro $(14,2 \%)$. 
Tabla 4.2

Clasificación de participantes según su estado civil, 2015

\begin{tabular}{lcc}
\hline Estado Civil & Frecuencia & Porcentaje \\
\hline Soltero & 72 & 31.0 \\
Casado & 118 & 50.9 \\
Divorciado & 9 & 3.9 \\
Otro & 33 & 14.2 \\
Total & 232 & 100.0 \\
\hline
\end{tabular}

Nota: Total de taxistas evaluados (232).

En lo que respecta al nivel de estudios alcanzados, la muestra se distribuye como se indica en la tabla 4.3. Del total de conductores que participaron en la investigación, 9 acabaron primaria (3,9\%), 54 culminaron la secundaria (23,3\%), 62 tienen estudios universitarios incompletos $(26,7 \%), 60$ han culminado una carrera universitaria $(25,9 \%)$ y 47 tienen estudios técnicos completos $(20,3 \%)$.

Tabla 4.3

Clasificación de participantes según el nivel de estudios alcanzados, 2015

\begin{tabular}{lcc}
\hline Nivel de estudios alcanzado & Frecuencia & Porcentaje \\
\hline Primaria & 9 & 3.9 \\
Secundaria completa & 54 & 23.3 \\
Universitario incompleto & 62 & 26.7 \\
Universitario completo & 60 & 25.9 \\
Técnico completo & 47 & 20.3 \\
Total & 232 & 100.0 \\
\hline
\end{tabular}

Nota: Total de taxistas evaluados (232). 


\subsection{Técnicas de recolección de información}

\subsubsection{Inventario Burnout de Maslach (MBI)}

El inventario Burnout de Maslach fue creado en 1981, este inventario propone, inicialmente, que el síndrome se presenta en profesionales de instituciones de servicios sociales, sanitarios y educativos. Quienes, producto del desgaste, sufren al implicarse durante muchas horas en los problemas de las personas con las que se relacionan profesionalmente. Los autores caracterizan el síndrome por 3 áreas que evalúa la prueba (Maslach \& Jackson, 1986).

Agotamiento emocional: Los elementos describen los sentimientos de una persona emocionalmente exhausta por el propio trabajo.

Despersonalización: Los elementos de esta área describen una respuesta fría hacia las personas que reciben los servicios del trabajador. La persona no se preocupa realmente por el ser humano con el que está tratando, pudiéndolo ver como un objeto impersonal.

Realización personal: Esta categoría contiene ítems que describen al individuo como una persona que se siente competente y con éxito en lo que realiza.

El instrumento está constituido por 22 ítems con un formato de respuesta en serie de tipo Likert de siete puntos (0, que significa Nunca y 6 que hace referencia a Todos los días). Asimismo en el lado izquierdo de la 
prueba se le pregunta al participante por su género, edad, estado civil, nivel de estudios alcanzados y tiempo de servicio.

Los niveles de cada dimensión del evaluado se obtienen al sumar todos los puntos anotados en los elementos de cada área correspondiente. El área de agotamiento emocional comprende nueve ítems; el área de despersonalización comprende cinco ítems y el área de realización personal comprende ocho ítems (tabla 4.4).

Tabla 4.4

Clasificación de ítems según las dimensiones del Inventario Burnout de Maslach (MBI)

Áreas Ítems

Agotamiento emocional $\quad 1,2,3,6,8,13,14,16,20$

Despersonalización

$5,10,11,15,22$

Realización personal $\quad 4,7,9,12,17,18,19,21$

Fuente: Inventario Burnout de Maslach (MBI), 1993.

En la dimensión de Agotamiento Emocional las puntuaciones de 27 o superiores serían indicativas de un alto nivel de Burnout, el intervalo entre 19 y 26 corresponderían a puntuaciones intermedias, mientras puntuaciones menores a 19 indican niveles de Burnout bajos o muy bajos.

En cuanto a la dimensión de Despersonalización, puntuaciones superiores a 10 serían nivel alto, de 6 a 9 medio y menor de 6 bajo grado de despersonalización. Finalmente, en la dimensión de Realización Personal de 0 
a 30 puntos indicaría baja realización personal, de 34 a 39 intermedia y superior a 40 sensación de logro (Maslach \& Jackson, 1993).

En cuanto las evidencias de confiabilidad halladas en la prueba original y descritas en el manual de la misma. Se encontraron evidencias de consistencia interna con respecto a las puntuaciones obtenidas según el coeficiente de alfa de Cronbach en una muestra de 1316 personas. Los índices que se obtuvieron son los siguientes: cansancio emocional $(\alpha=.90)$, despersonalización $(\alpha=$.79) y en realización personal $(\alpha=.71)$.

Las evidencias de validez de la prueba se hallaron a través del uso de análisis factoriales en diferentes muestras de grupos de profesionales, tales como: maestros, enfermeros y personal sanitario, trabajadores sociales, farmacéuticos, entre otros. Los resultados, en su mayoría, corroboraron la existencia de tres factores ortogonales que son los previamente mencionados: agotamiento emocional, despersonalización y falta de realización personal. (Maslach \& Jackson, 1986).

La prueba también ha sido adaptada psicométricamente al Perú por Fernández en el 2002 (ver Apéndice A). Se obtuvieron evidencias de validez referidas al contenido por criterio de jueces, se hizo una equivalencia lingüística al español utilizado en el país. Los resultados obtenidos, indicaron que todos los ítems alcanzaron niveles adecuados de significación estadística, por lo que fue posible trabajar con el instrumento sin realizar mayores modificaciones (Fernández, 2002).

Para hallar la evidencia de validez relacionado con el contenido de la prueba, se utilizó el coeficiente de $\mathrm{V}$ de Aiken. Este coeficiente alcanzó 
niveles de .89 a 1, por lo que la prueba contó con evidencias suficientes para poder ser aplicada (Escurra, 1988 citado en Fernández, 2002).

Con relación a los niveles de validez de constructo, Fernández realizó un análisis factorial confirmatorio (AFC) de la prueba, de modo que se pudo saber si se podían establecer los tres factores obtenidos en la versión original de la prueba. Los resultados demostraron que la estructura de tres factores tiene índices de ajuste adecuados $(\mathrm{GFI}=.98$ y AGFI $=.95)$ y por lo que se concluyó que el modelo es corroborado (Fernández, 2002).

Finalmente, se encontró un coeficiente de consistencia interna alfa de Cronbach de .78 para cansancio o agotamiento emocional, .76 para despersonalización y .74 para la disminución de la realización personal. Con esto se concluye que los ítems de cada área permiten obtener puntajes confiables (Fernández, 2002).

Después de lo anteriormente descrito, se puede corroborar que el inventario de Burnout de Maslach (MBI) cuenta con evidencias de validez y confiabilidad en el Perú, por lo que es factible utilizar las puntuaciones de dicho instrumento en la presente investigación. Los baremos utilizados son los utilizados por Fernández, quien otorgó los permisos necesarios para la utilización de los mismos en la presente investigación. 


\subsection{Procedimiento de recolección de datos}

Todos los procedimientos descritos a continuación fueron realizados tomando en cuenta un cronograma (Apéndice C) y presupuesto (Apéndice D) previamente definidos.

La prueba MBI ha sido administrada en distintos contextos en la sociedad limeña ya que se encontraron evidencias de validez y confiabilidad de la misma en la adaptación de Fernández (Fernández, 2002).

Para iniciar el procedimiento, se le entregó a la empresa de taxi elegida una carta a nombre de la Universidad de Lima solicitando la autorización para la administración de la prueba.

Luego de confirmado el permiso y recibir el consentimiento informado de forma verbal, pues la empresa no quiso dejar constancia de que se trabajó con su población, se aplicó la prueba al final de la capacitación inductiva de dicha empresa. La aplicación de la prueba se llevó en un periodo de un mes.

La prueba fue aplicada de manera grupal. Luego de brindar las instrucciones propias de cada evaluación, se preguntó a los conductores si entienden todos los enunciados de la prueba, para resolver dudas en caso las tengan. La resolución del inventario tuvo una duración aproximada de 10 minutos. 


\section{CAPITULO V: RESULTADOS}

En la Tabla 5.5 se presentan la media y la desviación estándar de las variables investigadas según los resultados de la muestra. Analizando los resultados de la evaluación a través del Inventario de Burnout de Maslach a un grupo de taxistas, se halló que la escala de agotamiento emocional alcanzó un promedio de 10.86 $(\mathrm{DE}=8,07)$, la escala de despersonalización un promedio de 4,08 $(\mathrm{DE}=4,07$; y la escala de realización personal (RP) se alcanzó un promedio de 40,44 (DE=8.07).

Tabla 5.5

Distribución de la muestra según las dimensiones de la prueba, 2015

\begin{tabular}{|l|llll|}
\hline & Mínimo & Máximo & Promedio & Desviación \\
\hline & & & & estándar \\
\hline Agotamiento & 0 & 40 & 10,86 & 8.072 \\
\hline emocional & 0 & 19 & 4,08 & 4.067 \\
\hline Despersonalización & 0 & 48 & 40,44 & 7.892 \\
Realización & 11 & & & 0 \\
\hline
\end{tabular}

En la Tabla 5.6 se presentan las puntuaciones de la muestra acumulada según percentiles (ver Apéndice B) y detalladas en cada una de las dimensiones de la prueba. A su vez, se separan las puntuaciones de cada dimensión en los niveles bajo, medio y alto según la clasificación indicada en el manual de la prueba. En la Figura 5.1 se muestra los resultados de la dimensión agotamiento emocional, en la Figura 5.2 
se muestra los resultados de la dimensión de despersonalización y en la Figura 5.3 se muestra los resultados de la dimensión de realización personal.

Tabla 5.6

Resultados por dimensiones según percentiles, 2015

\begin{tabular}{|c|c|c|c|}
\hline Percentiles & $\begin{array}{l}\text { Agotamiento } \\
\text { emocional }\end{array}$ & Despersonalización & $\begin{array}{c}\text { Realización } \\
\text { personal }\end{array}$ \\
\hline 1 & .00 & .00 & 11.33 \\
\hline 5 & .00 & .00 & 24.00 \\
\hline 10 & 2.00 & .00 & 30.00 \\
\hline 15 & 2.95 & .00 & 32.00 \\
\hline 20 & 4.00 & .00 & 35.00 \\
\hline 25 & 4.00 & .00 & 36.00 \\
\hline 30 & 6.00 & 1.00 & 38.00 \\
\hline 35 & 7.00 & 1.00 & 39.00 \\
\hline 40 & 7.20 & 2.00 & 40.00 \\
\hline 45 & 8.00 & 3.00 & 42.00 \\
\hline 50 & 9.00 & 3.00 & 42.00 \\
\hline 55 & 10.00 & 4.00 & 44.00 \\
\hline 60 & 11.00 & 5.00 & 44.00 \\
\hline 65 & 13.00 & 5.00 & 45.00 \\
\hline 70 & 14.00 & 6.00 & 47.00 \\
\hline 75 & 15.00 & 6.00 & 47.00 \\
\hline 80 & 16.40 & 7.00 & 48.00 \\
\hline 85 & 19.00 & 8.00 & 48.00 \\
\hline 90 & 22.00 & 10.00 & 48.00 \\
\hline 95 & 27.00 & 13.00 & 48.00 \\
\hline 99 & 39.00 & 16.00 & 48.00 \\
\hline
\end{tabular}

Nota: Total de taxistas evaluados (232). 
Figura 5.1 Resultados de la dimensión agotamiento emocional por niveles (\%)

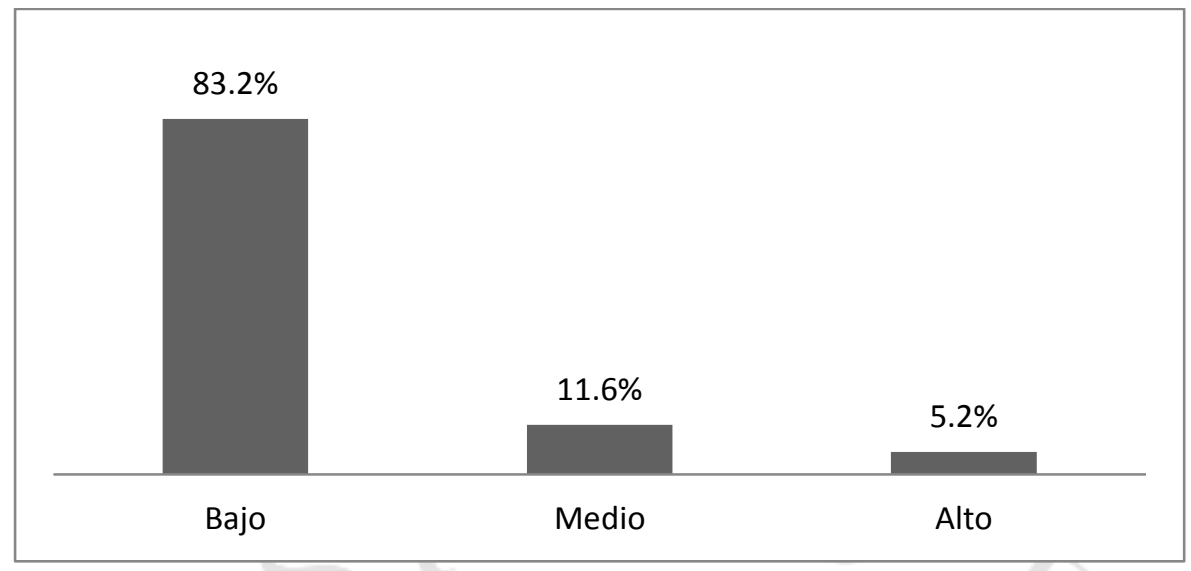

Nota: Total de taxistas evaluados (232).

Figura 5.2 Resultados de la dimensión despersonalización por niveles (\%)

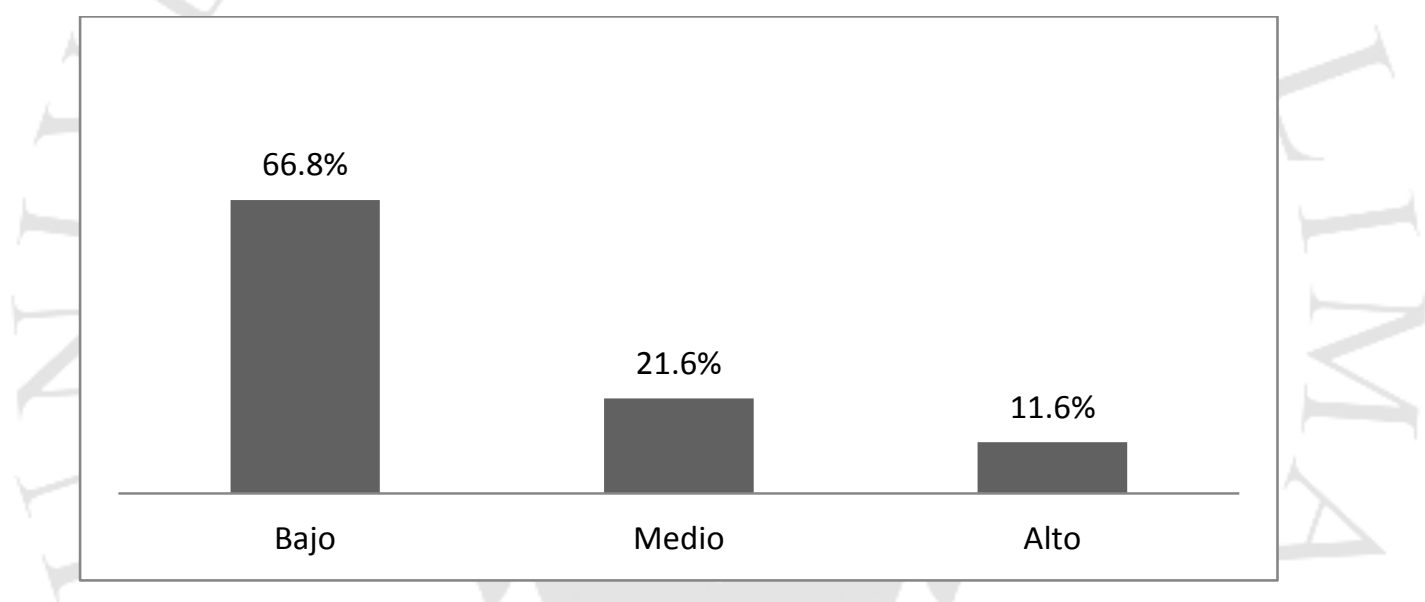

Nota: Total de taxistas evaluados (232).

Figura 5.3 Resultados de la dimensión realización personal por niveles (\%)

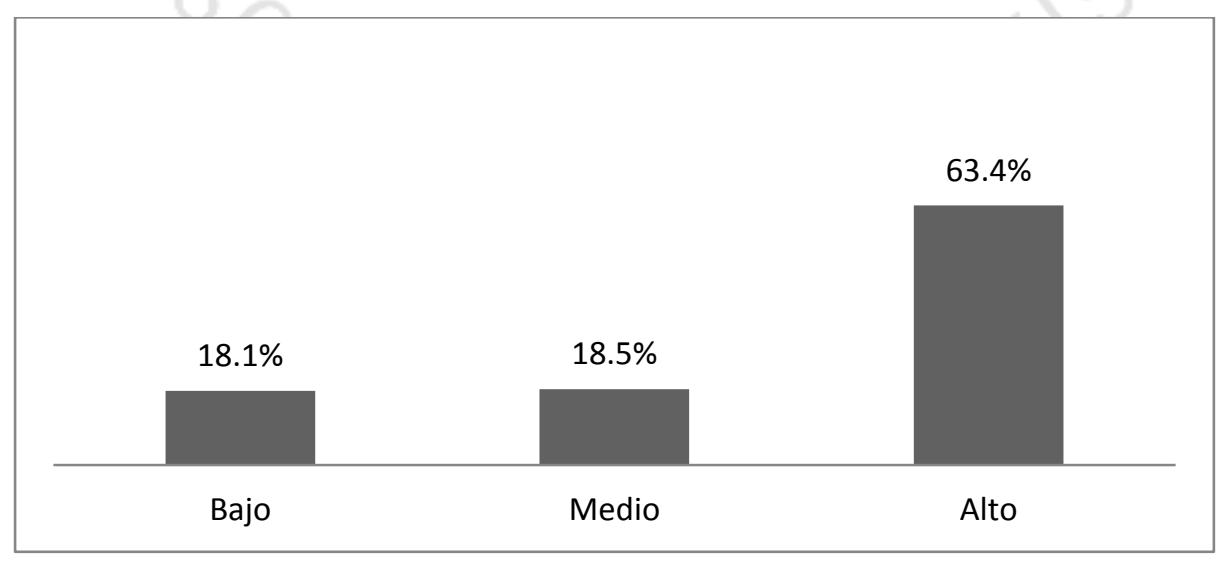

Nota: Total de taxistas evaluados (232). 
Asimismo, se hace un análisis para corroborar la presencia del síndrome en la población. Se comprobó cuantos de los conductores, presentan niveles altos de agotamiento emocional y despersonalización y bajos niveles de realización personal. La figura 5.4 se muestra los análisis correspondientes. Se obtiene que ninguno de los conductores presenta los puntajes que indican una alta probabilidad de padecer el síndrome en estudio. Se observa que 3.00\% de los conductores presentan altos niveles de agotamiento emocional y despersonalización, $0.4 \%$ alto agotamiento emocional y baja realización personal. Finalmente, 1.7\% de los conductores presentó altos niveles de despersonalización y baja realización personal.

De acuerdo a las puntuaciones indicadas en el manual de la prueba, $83.2 \%$ de los conductores presenta niveles bajos de Agotamiento emocional, 11.6\% niveles intermedios de agotamiento emocional mientras que 5.2\% presenta niveles altos de agotamiento emocional. En cuanto a la dimensión de Despersonalización, $66.8 \%$ de los conductores presenta niveles bajos, $21.6 \%$ niveles intermedios y $11.6 \%$ niveles altos. En la subescala de Realización personal, se aprecia a un $63.4 \%$ de los conductores sensación de alta realización, $18.5 \%$ con una realización personal intermedia y un $18.1 \%$ con puntuaciones indicadoras de baja realización personal. 
Figura 5.4 Resultados por cantidad de conductores con puntaciones indicadoras de la presencia del síndrome de Burnout en dos o más dimensiones (\%)

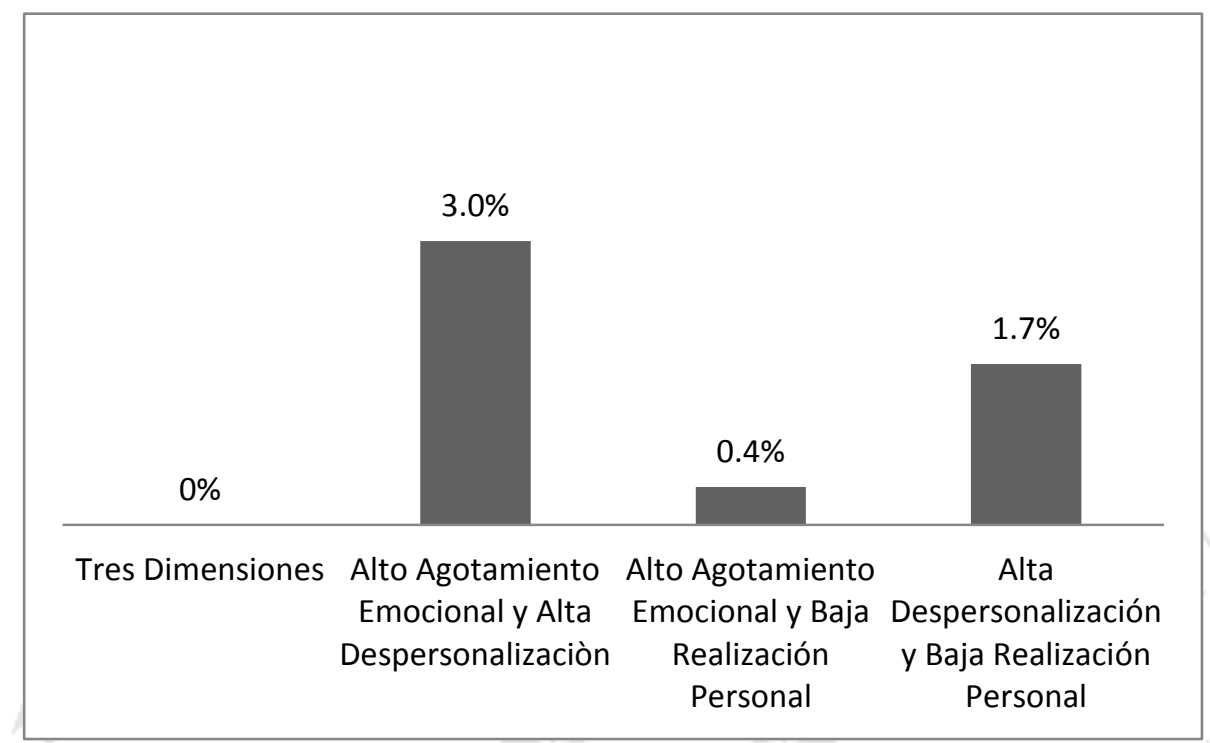

Nota: Total de taxistas evaluados (232).

Antes de realizar los análisis de asociación entre las variables se examinó la distribución de los puntajes obtenidos en la muestra. Para esto se utilizó el test de Shapiro-Wilk. Se realizó el test de acuerdo a cada variable demográfica que se mencionó en el apartado de objetivos. Como se puede ver en los resultados de la tabla 5.7, la tabla 5.8, la tabla 5.9 y la tabla 5.10, se encontraron que las variables demográficas edad, tiempo de servicio, nivel de estudios y estado civil no tienen una distribución normal, por lo que se optó por utilizar estadísticos no paramétricos para medir las relaciones, $\mathrm{p}>.05$. 
Tabla 5.7

Prueba de normalidad de los resultados según estado civil

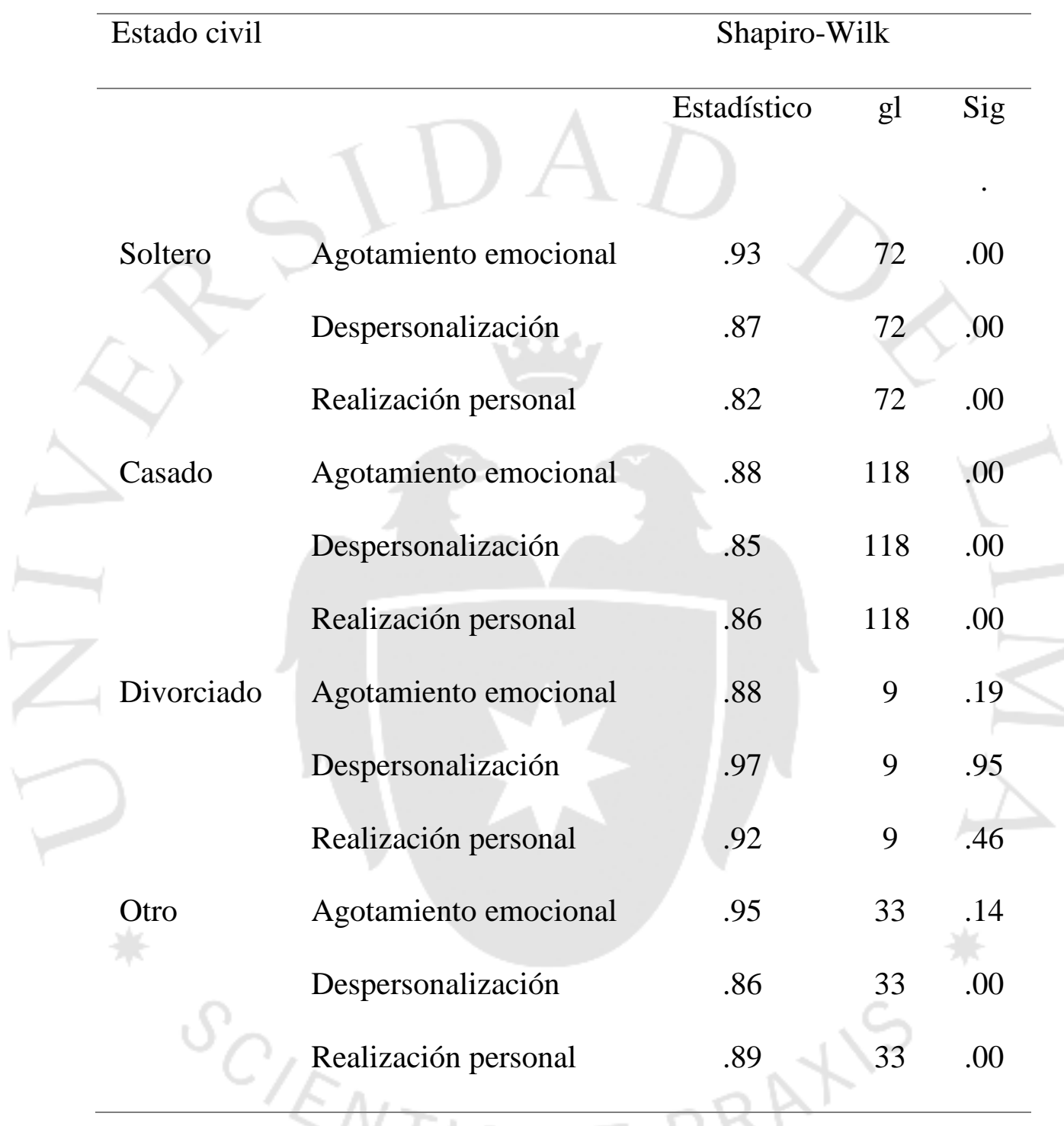

Nota: Total de taxistas evaluados (232). 
Tabla 5.8

Prueba de normalidad de los resultados según edad

\begin{tabular}{ll}
\hline Edad / Shapiro-Wilk & Sho
\end{tabular}

Años

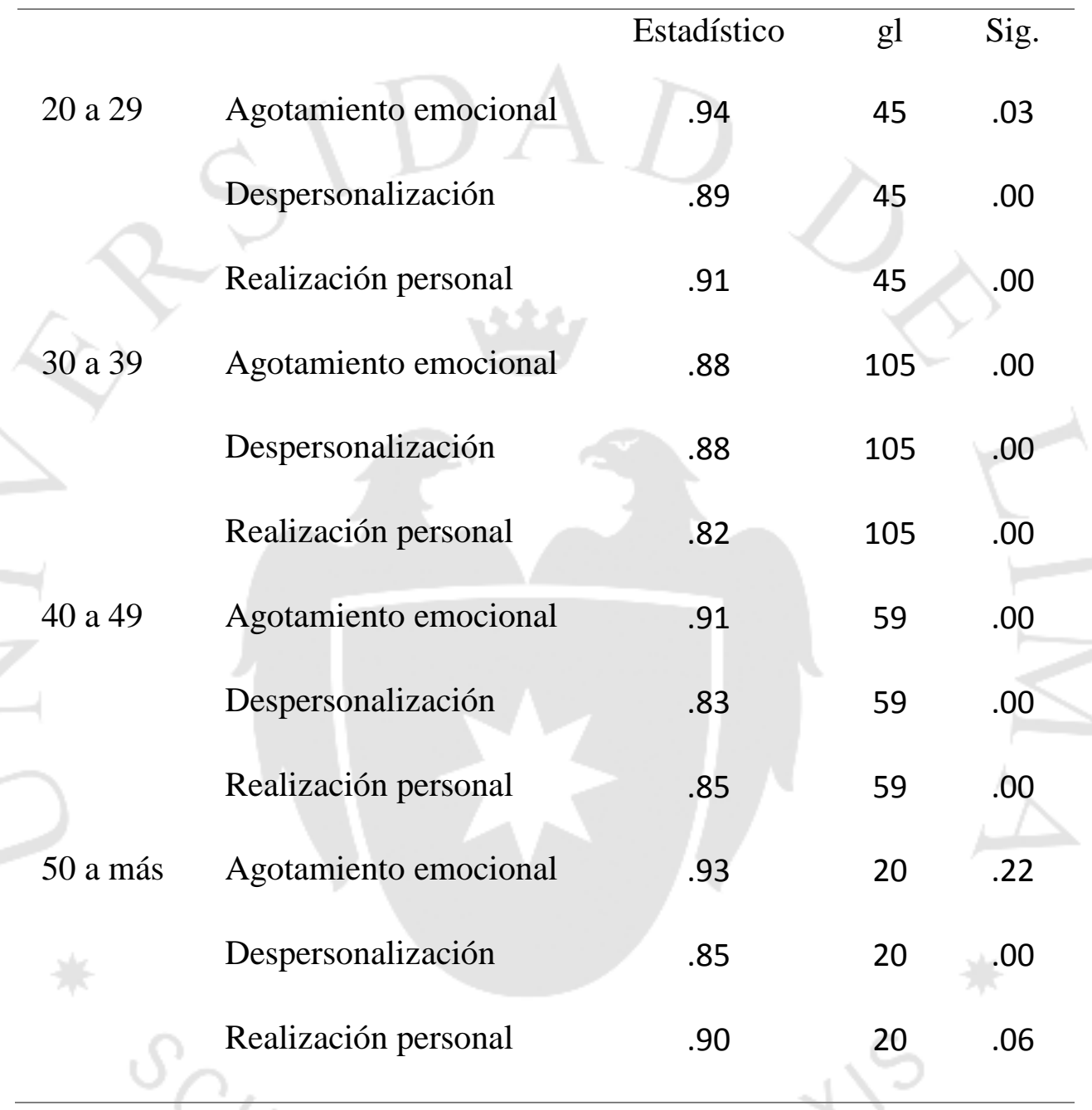

Nota: Total de taxistas evaluados (232). 
Tabla 5.9

Prueba de normalidad de la muestra según nivel de estudios alcanzados

\begin{tabular}{|c|c|c|c|c|}
\hline \multirow{2}{*}{$\begin{array}{l}\text { Nivel de } \\
\text { estudios }\end{array}$} & & \multicolumn{3}{|c|}{ Shapiro-Wilk } \\
\hline & & Estadístico & $\mathrm{gl}$ & Sig. \\
\hline Primaria & Agotamiento emocional & .91 & 9 & .32 \\
\hline Completa & Despersonalización & .81 & 9 & .03 \\
\hline & Realización personal & .90 & 9 & .27 \\
\hline Secundaria & Agotamiento emocional & .91 & 9 & .32 \\
\hline Completa & Despersonalización & .81 & 9 & .03 \\
\hline$\rightarrow$ & Realización personal & .90 & 9 & .27 \\
\hline Técnico & Agotamiento emocional & .94 & 47 & .03 \\
\hline Completo & Despersonalización & .88 & 47 & \\
\hline 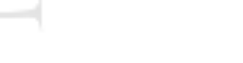 & Realización personal & .85 & 47 & .00 \\
\hline Universitario & Agotamiento emocional & .92 & 62 & .00 \\
\hline Incompleto & Despersonalización & .85 & 62 & .00 \\
\hline & Realización personal & .78 & 62 & .00 \\
\hline Universitario & Agotamiento emocional & .85 & 60 & .00 \\
\hline Completo & Despersonalización & .85 & 60 & .00 \\
\hline & Realización personal & .89 & 60 & .00 \\
\hline
\end{tabular}

Nota: Total de taxistas evaluados (232). 
Tabla 5.10

Prueba de normalidad de la muestra según los años de servicio

$\begin{array}{ll}\text { Tiempo de } & \text { Shapiro-Wilk }\end{array}$

servicio en años

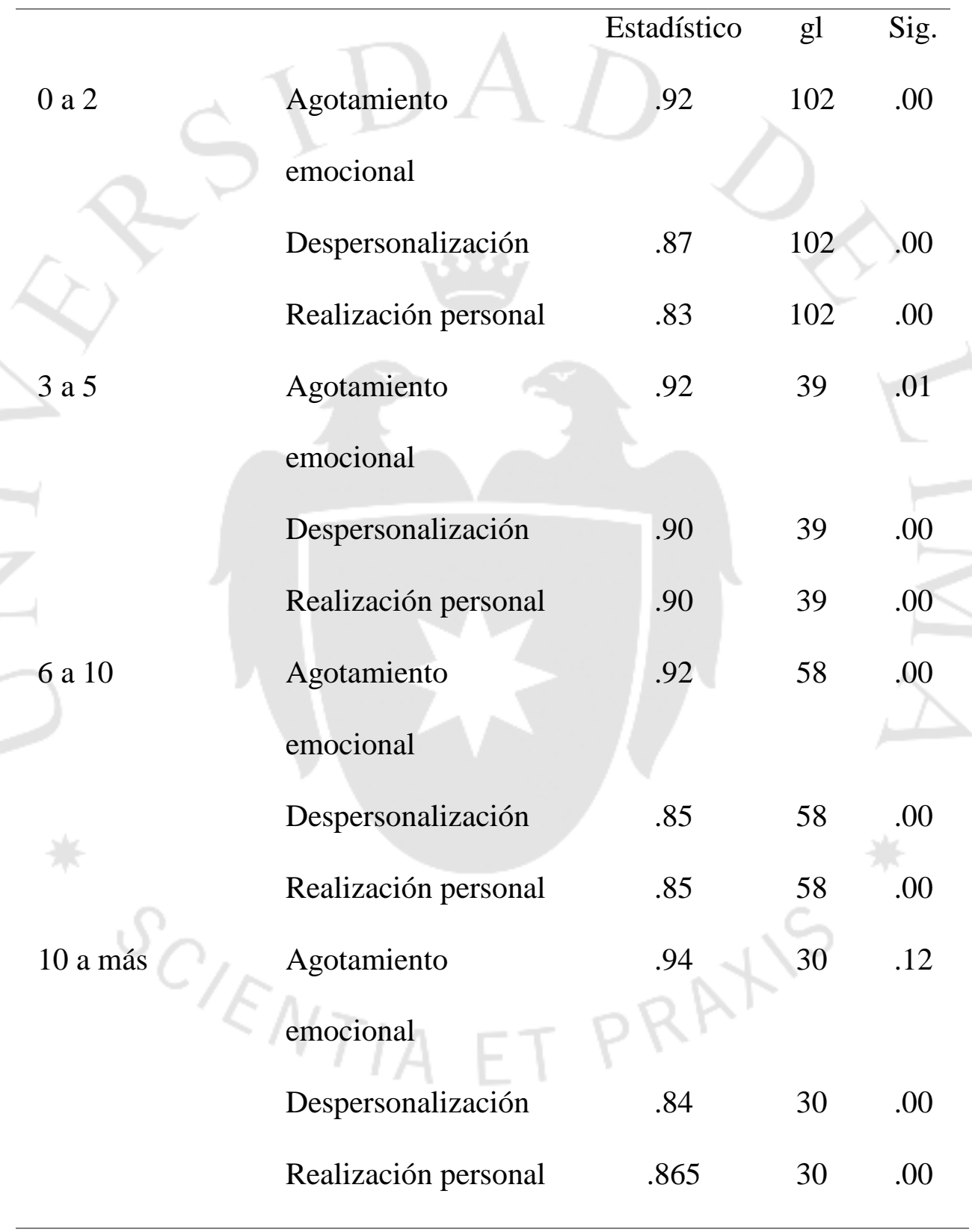

Nota: Total de taxistas evaluados (232). 
Habiendo hecho los análisis de distribución de la normalidad de la muestra, se pasaron a usar pruebas no paramétricas para medir la relación entre variables y la intensidad de las mismas. Los resultados obtenidos en lo que respecta al estado civil de los conductores demuestra que no se hallaron relaciones significativas en ninguno de los 3 factores de la prueba, $\mathrm{p}>.05$.

Se utilizó el estadístico Chi cuadrado para analizar la relación del estado civil con los niveles de agotamiento emocional $\mathrm{p}=.04$, con una intensidad baja $\mathrm{v}=.24$. Como se observa en la tabla 5.14, comparando los dos grupos más numerosos solteros ( $\mathrm{N}=72)$ y casados $(\mathrm{N}=118)$, los niveles de agotamiento emocional son mayores en el grupo de solteros. No se encontraron relaciones significativas entre las demás variables, $\mathrm{p}>.05$.

Tabla 5.11

Prueba de Chi cuadrado para medir la relación del estado civil con el nivel de agotamiento emocional de la prueba MBI

\begin{tabular}{lcccc}
\hline & Valor & gl & \multicolumn{2}{c}{ Sig. asintótica } \\
\hline Chi-cuadrado de Pearson & $12.90^{\mathrm{a}}$ & 6 & .04 \\
Razón de verosimilitud & 14.82 & 6 & .02 \\
Asociación lineal por lineal & .77 & 1 & .37 \\
N de casos válidos & 232 & & .44 \\
V de Cramer & .23 & & .47
\end{tabular}

Nota: Total de taxistas evaluados (232). 
Tabla 5.12

Prueba de Chi cuadrado para medir la relación del estado civil con el nivel de despersonalización de la prueba MBI

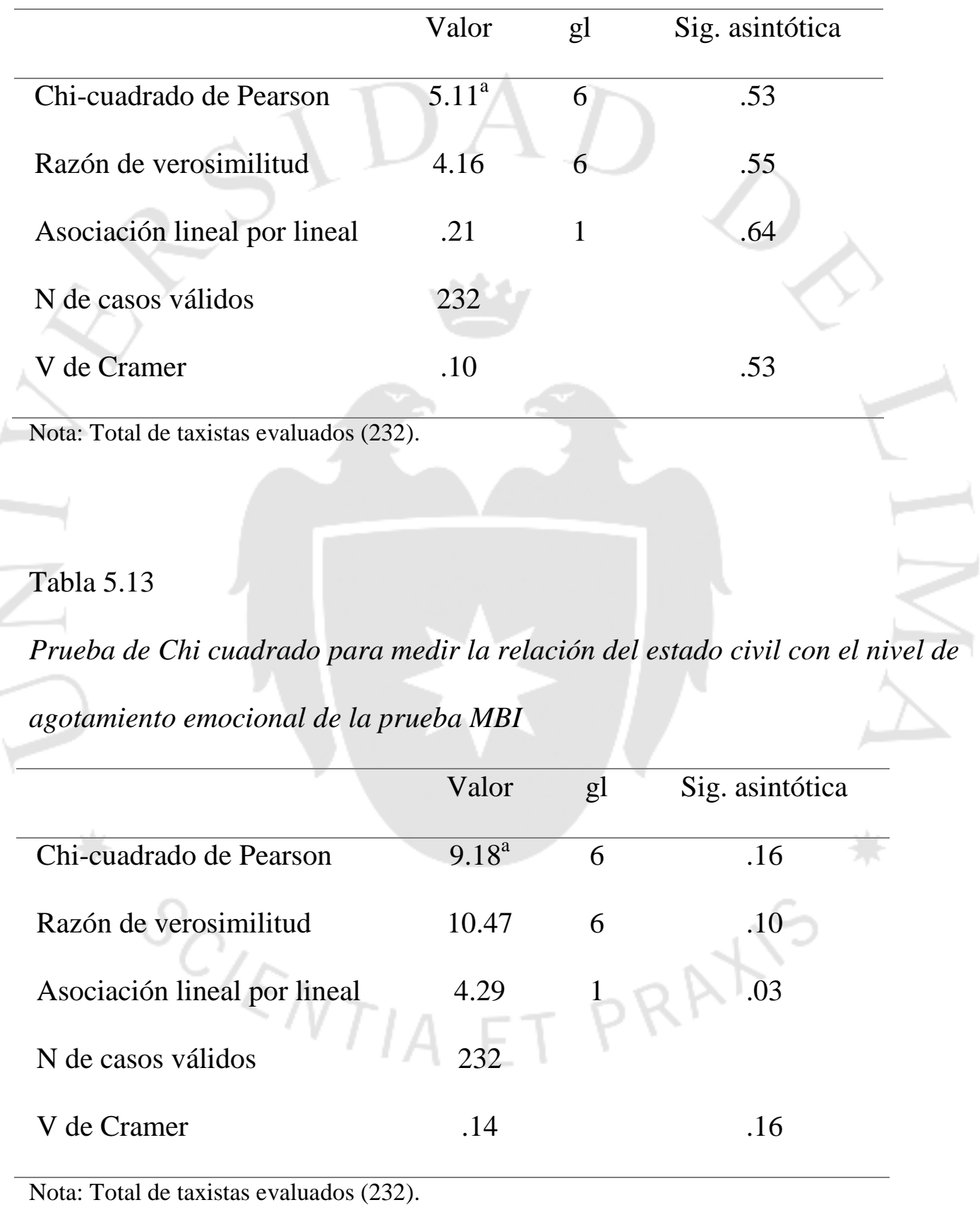


Tabla 5.14

Porcentaje de agotamiento emocional según estado civil por niveles

\begin{tabular}{lcccc}
\hline Estado Civil & \multicolumn{3}{c}{ Niveles Agotamiento } & Total \\
\hline & Bajo & Medio & Alto & \\
Soltero & $75 \%$ & $19 \%$ & $6 \%$ & 72 \\
Casado & $89 \%$ & $5 \%$ & $6 \%$ & 118 \\
Divorciado & $78 \%$ & $11 \%$ & $11 \%$ & 9 \\
Otro & $82 \%$ & $18 \%$ & $0 \%$ & 33 \\
Total & 193 & 27 & 12 & 232 \\
\hline Nota: Total de taxistas evaluados (232). & & & \\
\hline
\end{tabular}

En cuanto a la relación entre la edad de la muestra y los niveles de Burnout.

Cuando se hace el análisis haciendo agrupaciones por edad, se encuentra que existe una relación significativa inversa de baja intensidad entre la edad de los conductores y los niveles de agotamiento emocional $\mathrm{p}=.005 \mathrm{y}$ despersonalización $\mathrm{p}=.035$. Es decir, mientras menos edad tienen los conductores presentan mayores niveles de agotamiento emocional y despersonalización. Asimismo existe una relación significativa de baja intensidad entre la edad de los conductores y los niveles de realización personal, siendo los conductores de menor edad quienes presentan menores niveles de realización, tal como se muestra en la tabla 5.15. 
Tabla 5.15

Coeficiente de correlación de Spearman para medir la relación de la edad con las variables de la prueba MBI.

\begin{tabular}{lccc}
\hline & $\begin{array}{c}\text { Agotamiento } \\
\text { emocional }\end{array}$ & Despersonalización & Realización \\
& & & personal \\
\hline Coeficiente de & $-.185^{* *}$ & $-.138^{*}$ & $.157^{*}$ \\
correlación & & & \\
Sig. (bilateral) & .005 & .035 & .017 \\
$\mathrm{~N}$ & 232 & 232 & 232 \\
\hline **. La correlación es significativa en el nivel 0,01 (2 colas). & \\
*. La correlación es significativa en el nivel 0,05 (2 colas). &
\end{tabular}

Las tablas 5.16, 5.17 y 5.18 muestran que no se encontró relación entre el nivel de estudios alcanzados y las dimensiones de Burnout del MBI al utilizar el coeficiente Chi cuadrado de Pearson, $\mathrm{p}>.05$.

Tabla 5.16

Relación entre la dimensión agotamiento emocional y el nivel de estudios

\begin{tabular}{lcccc}
\hline & Valor & $\mathrm{gl}$ & Sig. asintótica \\
\hline Chi-cuadrado de Pearson & $5.89 \mathrm{a}$ & 8 & .65 \\
Razón de verosimilitud & 6.54 & 8 & .58 \\
Asociación lineal por lineal & .29 & 1 & .59 \\
N de casos válidos & 232 & & \\
\hline
\end{tabular}


Tabla 5.17

Relación entre la dimensión despersonalización y el nivel de estudios

Valor gl Sig. Asintótica

(2 caras)

Chi-cuadrado de Pearson

$5.28 \mathrm{a}$

8 .72

Razón de verosimilitud

6.27

8

.61

Asociación lineal por lineal

$.02-1$

.88

$\mathrm{N}$ de casos válidos

232

Tabla 5.18

Relación entre la dimensión realización personal y el nivel de estudios

Valor $\quad$ gl Sig. asintótica (2

caras)

Chi-cuadrado de Pearson

$9.24^{\mathrm{a}}-8$

.32

Razón de verosimilitud

$9.31 \quad 8$

.31

Asociación lineal por lineal

$.02 \quad 1$

.87

$\mathrm{N}$ de casos válidos

232

De la misma manera, se encontró que no existe relación significativa entre el tiempo que los conductores llevan ofreciendo el servicio de taxi y las variables de la prueba MBI utilizando el coeficiente de correlación de Spearman, p > .05. 
Tabla 5.19

Coeficiente de correlación de Spearman para analizar la relación del tiempo de servicio con las dimensiones de la prueba MBI

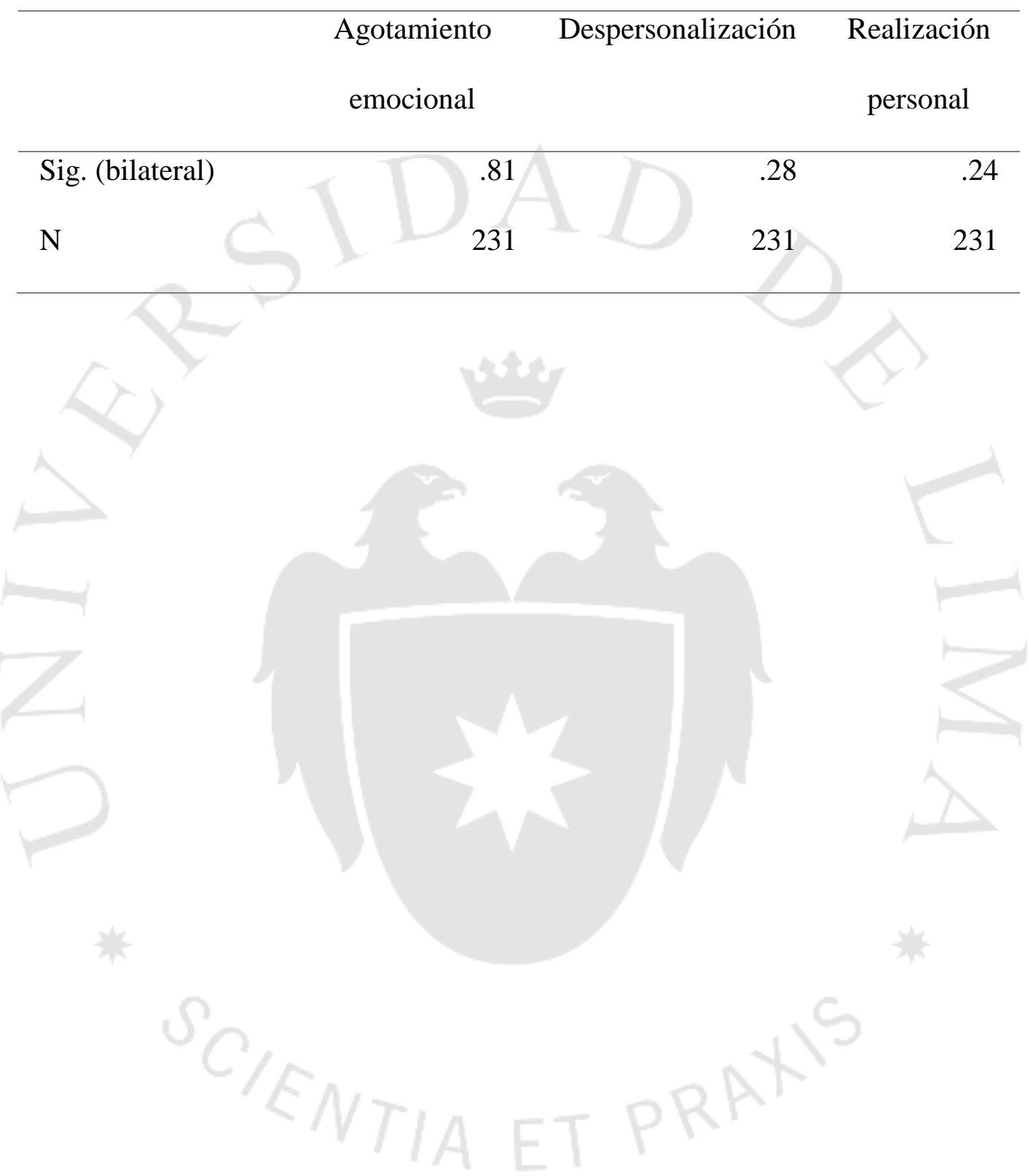




\section{CAPITULO VI: DISCUSIÓN DE RESULTADOS}

Este estudio se presenta como uno de los primeros en buscar la presencia del síndrome y su relación con otras variables en la población de taxistas en el Perú.

Se plantearon 14 hipótesis: la primera es que los taxistas de una empresa de Lima metropolitana presentaban puntuaciones indicadoras del síndrome de Burnout, la segunda suponía que por lo menos alguna de las dimensiones indicadoras del síndrome tendría un importante número de conductores en el nivel propio del síndrome. Las siguientes 12 suponían que existían relaciones significativas entre cada una de las 3 dimensiones del síndrome de Burnout y cada una de las siguientes variables demográficas: edad, tiempo haciendo taxi, estado civil y el nivel de estudios alcanzado

Estas hipótesis fueron propuestas en base a investigaciones pasadas que buscan conocer a mayor profundidad la salud mental de los conductores de Lima metropolitana (Arias \&/Jimenes, 2012) (Mallma-Acuña, Rivera-Yngunza, RodasSimbron, \& Farro-Peña, 2013) (Salazar Concepción \& Pereda De los Santos, 2010). Asimismo la búsqueda de la relación con variables demográficas, parte de estudios pasados donde se investiga la relación de altos niveles de Burnout con ciertas variables demográficas (Kirsi, y otros, 2006) (Castillo, Benavente, Arnold, \& Cruz, 
2012) (Juárez-García, Idrovo, Camacho-Avila, \& Plasencia-Reyes, 2014) (Ramos, Aldrete, Medina, \& León, 2013).

Los resultados encontrados fueron los siguientes: De acuerdo a las puntuaciones indicadas en el manual de la prueba, 5.2\% de los conductores presentan niveles altos de agotamiento emocional, $11.6 \%$ niveles altos en la dimensión despersonalización y $18.1 \%$ niveles bajos de realización personal. Por separado, ninguno de los conductores presentó la configuración indicadora del síndrome (alto nivel de agotamiento emocional y despersonalización y bajo nivel de realización personal)

En cuanto a las relaciones entre las dimensiones del Burnout y las variables demográficas se encontró que existen las siguientes relaciones significativas: existe una relación significativa entre los niveles de agotamiento emocional y el estado civil, siendo mayores los niveles de agotamiento emocional en el grupo de solteros.

Asimismo, al utilizar el estadístico de correlación de Spearman se comprueba que existe una relación significativa inversa de baja intensidad entre la edad de los conductores y sus niveles de agotamiento emocional y despersonalización. De la misma manera, una relación significativa positiva entre la edad y los niveles de realización personal.

En cuanto a la primera y segunda hipótesis los resultados en general demuestran que los conductores de la muestra presentan bajos niveles de agotamiento emocional y despersonalización; hay un porcentaje más alto de conductores con baja realización personal, pero aun así no supera el 20\% del total. Estos niveles pueden deberse a múltiples causas, la primera y considerada como una limitación del presente estudio, es que la muestra considerada no toma en cuenta a taxistas informales 
quienes se ven en situaciones menos favorables y que, por lo tanto, se ven más propensos a desarrollar síntomas de estrés. Por otra parte algunos estudios denotan algunos beneficios del conductor de taxi, beneficios que podrían tener una mayor fuerza en el sentido de bienestar frente a los elementos adversos del día a día como el tráfico y la inseguridad. Esta última idea se desarrollará en los siguientes párrafos.

El trabajo como taxista aparece como una fuente de ingresos frente al precario sistema laboral de nuestro país y de los países en desarrollo en general. Un sistema conocido por condiciones desfavorables para el trabajador, empresas de baja productividad, falta de cumplimiento de las leyes y normas, entre otras. Llevando a cabo una labor como taxista, la persona no solo está fuera de este sistema que no le otorga beneficios, sino que tiene una mayor flexibilidad de horarios; una mayor autonomía, pues no deben reportarle a un jefe; una mayor estabilidad, pues su trabajo depende únicamente de ellos y su propias herramientas; finalmente, una mayor liquidez, pues los ingresos se reciben en el momento y se ven exentos de impuestos (Perry, Maloney, Fajnzylber, Mason, \& Saavedra-Chanduvi, 2007). En base a los puntos previamente descritos se podría entender el saludable estado mental de los conductores

Ante lo mencionado con anterioridad como factor explicativo de los resultados y específicamente en cuanto a los altos niveles de realización personal hay algunas investigaciones adicionales a agregar. Algunos estudios aseveran que el fin por el que las personas trabajan es el poder mantener un estilo de vida donde se pueda obtener lo básico y lo que se desea. Por lo que si una persona obtiene extrínsecamente lo que desea podría sentirse realizada. De ahí que investigaciones encuentran una relación positiva entre las aspiraciones extrínsecas y la satisfacción personal (Brdar, Rijavec, \& Miljkovic, 2009; Kasser, 2005). Si bien también son sumamente 
importantes ciertas variables intrínsecas para el entendimiento de la percepción de realización de cada persona, en el presente estudio no se pudo tener información que pueda sugerir los factores internos que expliquen la alta realización personal de la mayoría de conductores.

Por otro lado, en lo que respecta a las variables extrínsecas, más fácilmente observables. La empresa donde se realizó la muestra, indica que los conductores que cumplen con una jornada de 10 horas, 6 veces por semana tienen un ingreso promedio de S/ 3,000. Siendo el sueldo mínimo a la fecha S/ 850 (MTPE, 2016) y tomando en cuenta los estudios previamente mencionados, el ingreso mensual de los conductores es el suficiente para poderles brindar una realización personal alta o media.

En cuanto a los bajos niveles de despersonalización y agotamiento emocional. Estos denotan que la relación pasajero-conductor no se encuentra desgastada. Se puede presumir que la relación podría funcionar como un paliativo al estrés que produce el tráfico y la inseguridad en vez de un agravante. No obstante no existen investigaciones antecedentes que puedan sustentar esta afirmación. Es necesaria la exploración a profundidad de esta relación y las consecuencias que pueden surgir a partir de la misma.

La variable que presenta una mayor cantidad de relaciones significativas es la variable edad, siendo los conductores de menor edad quienes en promedio tienen puntajes más cercanos a los que indican la presencia del síndrome. Estos hallazgos contradicen investigaciones antecedentes utilizadas para esta investigación donde se encontró que las poblaciones de mayor edad eran las que presentaban mayores niveles de estrés laboral (Juárez-García, Idrovo, Camacho-Avila, \& Plasencia-Reyes, 2014) (Ramos, Aldrete, Medina, \& León, 2013). 
Para analizar la relación de la percepción del estrés de acuerdo a la generación en la que nacieron los participantes resulta interesante la encuesta que realiza anualmente la APA. Al igual que las ediciones de los últimos 5 años al comparar la percepción de estrés de acuerdo a 4 generaciones, millenials (18-33), generación x (34 - 47), baby boomers (48 -66) maduros (67 a más). Los resultados arrojan que la percepción de estrés es mayor en las generaciones menores. Siendo los millenials quienes reportan los mayores niveles de estrés, ellos identifican como a su mayor estresor el trabajo (APA, 2016). No existen estudios realizados en el medio peruano a la fecha; no obstante, el informe de la APA apoya lo encontrado.

Siguiendo el informe de la APA, los millenials en su mayoría difieren con la generación de sus padres en cuanto a la aproximación hacia el trabajo. Mientras que los baby boomers le otorgan una importancia fundamental al trabajo, los millenials reportan el trabajo como su mayor estresor. Entendiendo al Burnout como una variación de estrés laboral se explica que existan mayores niveles de agotamiento emocional y despersonalización en los conductores de menor edad.

En cuanto a la ausencia de relación entre las dimensiones de burnout y el tiempo de servicio que llevan prestando los conductores. Algunos factores que pueden participar aquí, es que independientemente de su trabajo brindando el servicio de taxi, la población elegida ya tiene experiencia conduciendo en esta ciudad con anterioridad. Teniendo en cuenta que la única variable nueva es el llevar pasajeros, se entiende que no haya mayores diferencias, sobre todo porque en base a los resultados obtenidos se puede observar que los pasajeros no tienen mayor implicancia en el malestar de los conductores, al menos con lo referido a la presencia del Burnout.

En cuanto a la relación encontrada entre los conductores cuyo estado civil es soltero y mayores niveles de agotamiento emocional, se confirma lo mencionado en 
las investigaciones antecedentes que indican que los hombres con una pareja estable tienen, en promedio, menores niveles de estrés que sus pares solteros (Juárez-García, Idrovo, Camacho-Avila, \& Plasencia-Reyes, 2014), (Kirsi, y otros, 2006).

Finalmente, tampoco se encontraron relaciones entre el nivel de estudios alcanzado y ninguna de las tres dimensiones del Burnout. Es difícil entender la poca influencia que esta variable tiene, sobre todo en lo que respecta a los niveles de realización personal. Se presume nuevamente que los factores propios del trabajo., frente al sistema laboral existente en Lima metropolitana, pueden tener un mayor peso a la hora de la aceptación de trabajar como conductor de taxi frente a la labor de su propia profesión u oficio.

\subsection{Limitaciones}

Son limitaciones para este estudio, el poco tiempo que disponen los conductores de taxi, motivo por el cual solo se utiliza una herramienta de investigación. Esto impide que la investigación tenga un mayor alcance y una mayor cantidad de información cualitativa y cuantitativa de la población en estudio.

Asimismo la muestra con la que se podrá tener contacto no incluye a los taxistas que trabajan de manera informal. Estos últimos, podrían estar en condiciones más desfavorables para la salud mental y por lo tanto, pueden ser más proclives a padecer el síndrome en estudio.

Por otra parte, la generalización de resultados se verá perjudicada ya que por motivos de accesibilidad a la población sólo se pudo elegir a una empresa de taxi. Otro factor en contra es la herramienta de recolección de información, que por su 
naturaleza de cuestionario de autopercepción, implica una mayor dificultad en cuanto al control del factor de honestidad o deseabilidad social 


\section{CAPITULO VII: CONCLUSIONES}

- Ninguno de los conductores de la muestra presentó la configuración indicadora del síndrome (altos niveles de agotamiento emocional y despersonalización y bajo nivel de realización personal)

- De acuerdo a las puntuaciones indicadas en el manual de la prueba, 5.2\% de los conductores presentan niveles altos de agotamiento emocional, $11.6 \%$ niveles altos en la dimensión despersonalización y $18.1 \%$ niveles bajos de realización personal.

- Existe una relación significativa entre los niveles de agotamiento emocional y el estado civil, siendo mayores los niveles de agotamiento emocional en el grupo de solteros.

- Existe una relación significativa inversa de baja intensidad entre la edad de los conductores y sus niveles de agotamiento emocional y despersonalización. Asimismo una relación significativa positiva entre la edad y los niveles de realización personal

- No se encontraron relaciones significativas entre el tiempo de servicio y ninguna de las dimensiones del síndrome.

- No se encontraron relaciones significativas entre el nivel de estudios alcanzado y ninguna de las dimensiones del síndrome. 
- Se hipotetiza como explicación a los bajos niveles de agotamiento emocional, bajos niveles de despersonalización y altos niveles de realización personal obtenidos. Que el trabajo como taxista representa una alternativa de subempleo al sistema laboral precario del Perú y que pese a que existan condiciones adversas, como el tráfico o la inseguridad en su día a día, este trabajo les permite tener una mayor flexibilidad de horarios; una mayor autonomía, una mayor estabilidad y una mayor liquidez.

- Se sigue desconociendo si ante las altas tasas de siniestralidad existen variables psicológicas que subyacen como posibles causas.

- Los resultados obtenidos sugieren que la relación conductor-pasajero no está desgastada en la población elegida.

- Se identifica que las generaciones más jóvenes parecen tener una mayor vulnerabilidad a desarrollar el síndrome por lo que es necesario tener una aproximación y mayor investigación en el grupo mencionado. 


\section{CAPITULO VII: RECOMENDACIONES}

- Se recomienda, para futuras investigaciones, buscar una muestra más grande para poder generalizar los resultados para la población de Lima.

- Se recomienda investigar con otras aproximaciones o constructos la relación conductor-pasajero donde en muchas ocasiones se observa un trato y/o relación displicente

- La presente investigación le permite a la psicología clínica preocuparse por el bienestar mental del conductor, si bien los resultados denotan que en la totalidad de la muestra de conductores la presencia del síndrome es inexistente, es necesario que se desarrollen programas de intervención o prevención para esta población, pues como se mencionó son parte de la tercera causa de muerte en el país

- En cuanto a la psicología organizacional, esta investigación permite denotar a las empresas dedicadas al rubro de transporte que es necesario trabajar en el área de capacitación de sus conductores. Entendiendo la alta siniestralidad que ocurre en Lima y la ausencia de una explicación causal a tantas fallas. Se debe trabajar en el desarrollo del conductor al paralelo que se investigue cuáles son los problemas que aquejan a los conductores. 
- En lo que respecta a la psicología social, esta investigación pone en descubierto que la percepción de estrés por generaciones no ha sido estudiado en el país. Es necesario empezar a tomar aproximaciones precisas según las motivaciones y percepciones generacionales para el desarrollo psicosocial en los próximos años.

- Asimismo, la psicología educativa necesita preocuparse por crear programas educativos para el desarrollo de empatía y comportamiento vial. Las altas tasas de siniestralidad y la poca investigación existente en la población de conductores. Indica un urgente y arduo trabajo si se quiere tener una ciudad más educada y ordenada.

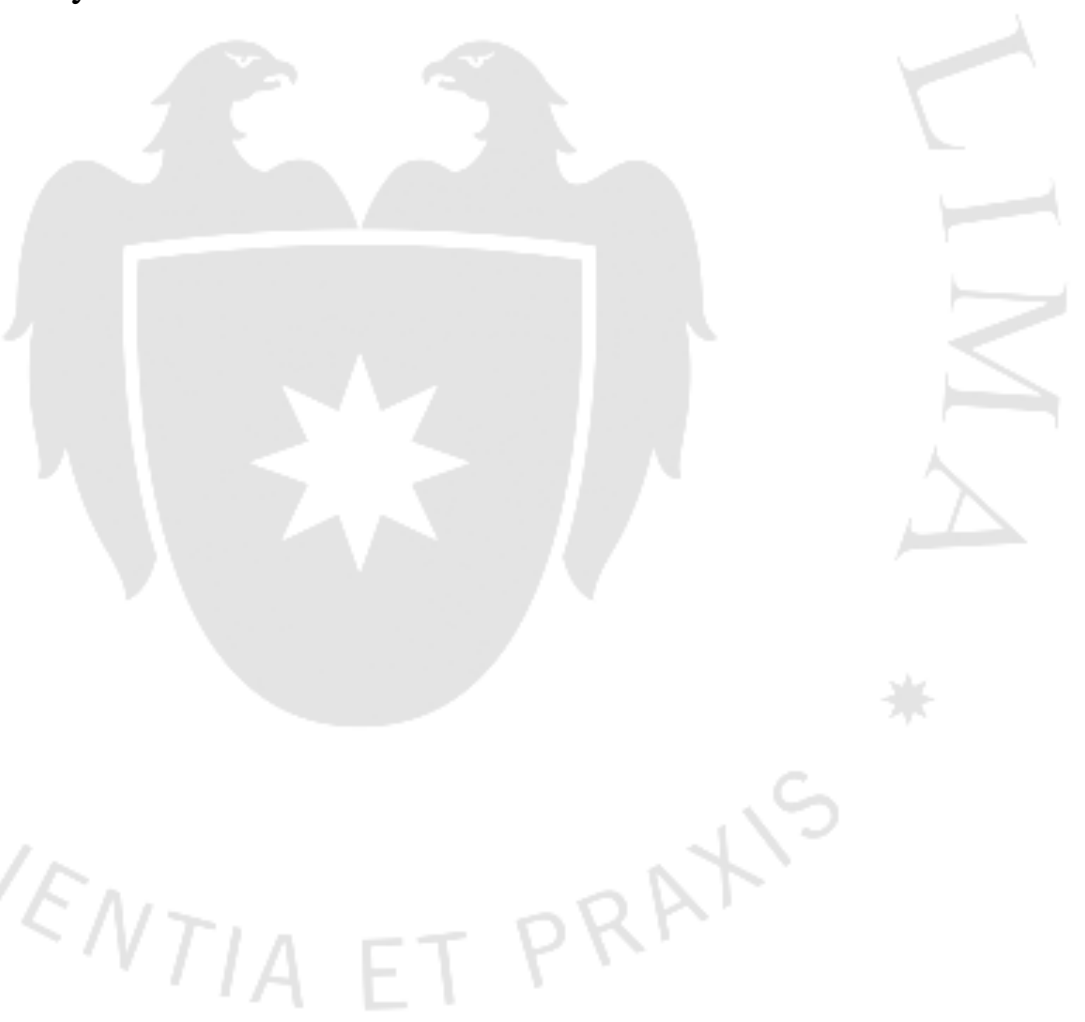




\section{REFERENCIAS Y BIBLIOGRAFÍA}

APA. (2016). Stress in America: The impact of discrimination. Stress in America Survey.

Arias Gallegos, W. L., Mendoza del Solar, L., \& Masias Salinas, M. (2013). Síndrome de

Burnout en conductores de transporte público de la ciudad de Arequipa. Revista

Peruana de Psicología y Trabajo Social, 2(2), 111-122.

Arias, W. L., \& Jimenes, N. A. (2012). Estrés crónico en el trabajo: Estudios del síndrome de Burnout en Arequipa. Universidad Católica de San Pablo.

Bosqued, M. (2008). Quemados, El síndrome del Burnout Qué es y cómo superarlo.

Barcelona: Ediciones Paidós Ibérica, S.A.

Brdar, I., Rijavec, M., \& Miljkovic, D. (2009). Life Goals and Well - Being: Are Extrinsic. Psychological Topics, 18(2), 317 -334.

Campillo Álvarez, J. E. (2012). El mono asustado. Barcelona: Crítica.

Castillo, A., Benavente, S., Arnold, J., \& Cruz, C. (2012). Presencia de síndrome de Burnout en hospital El Pino y su relación con variables epidemiológicas. Revista ANACEM, 6(1), 9-13.

Cherniss, C. (1981). Professional Burnout in Human Service Organizations. En M. Bosqued, Quemados El síndrome del Burnout Qué es y cómo superarlo (pág. 20). Barcelona: Ediciones Paidós Ibérica, S.A.

Cortés Zábala, Z. Y. (2009). Evaluación del sindrome de bournout y diseño de medidas para prevención de accidentalidad en el gremio de conductores de la empresa Transsander (Tesis para optar el título de psicóloga). Universidad Pontificia Bolivariana. 
Edelwich, J., \& Brodsky, A. (1980). Burn-out:Stages of disillusionment in the helping professions. En P. R. Gil-Monte (Ed), El síndrome de quemarse por el trabajo (Burnout) Una enfermedad laboral en la sociedad del bienestar (págs. 203-205). Nueva York: Human Science Press.

Fernández, M. (2002). Inventario Burnout de Maslach (MBI). Realidad psicosocial del maestro de primaria, 5, 115-118.

García Izquierdo, M. (1993). El estrés en contextos laborales: efectos psicológicos de los nuevos estresores. En J. Buendía Vidal (Ed), Estrés y psicopatología (págs. 26-38). Madrid: Ediciones Pirámide.

Gil-Monte, P. R. (2011). El síndrome de quemarse por el trabajo (Burnout). Madrid: Ediciones Pirámide.

Golembiewski, R. T., \& Munzenrider, R. (1988). Phases of Burnout: Developments in concepts and appications. Westport: Praeger.

González Ramírez, M., Landero Hernández, R., Maruris Reducindo, M., Cortés Genchi, P., Godínez Jaimes, F., \& Vega Mendoza, R. (2013). Estrés cotidiano en trabajadores del volante. Summa psicología, 10(1), 85-90.

Hernández, S., Fernández, C., \& Baptista, L. (2014). Metodología de la investigación (6a ed.). México: McGraw-Hill.

Houtman, I., \& Kompier, M. (2001). Trabajo y salud mental. En OIT, Enciclopedia de salud y seguridad en el trabajo (págs. 52-55). Madrid: Ministerio de Trabajo y Asuntos Sociales. 
INEI. (2015). Población estimada y proyectada por sexo y tasa de crecimiento, según años calendarios. Obtenido de www.ine.gob.pe

Juárez-García, A., Idrovo, Á., Camacho-Avila, A., \& Plasencia-Reyes, O. (2014). Síndrome de Burnout en población mexicana: Una revisión sistémica. Salud mental, 37(2), 159176.

Kasser, T. (2005). Personal Aspirations, The "Good Life" and the law. Associate Professor of, 10(1), 34-47.

Kirsi, A., Tieja, H. I., Kalimo, R., Nykyri, E., Koskinen, S., Aromaa, A., \& Lonnqvist, J. (2006). Burnout in general population. Social Psychiarty \& Psychiatric Epidemiology, 41(1), 11-17.

Lima cómo vamos. (2013). Lima cómo vamos. Obtenido de http://www.limacomovamos.org/cm/wp-content/uploads/2013/10/movilidad.pdf

Mallma-Acuña, A., Rivera-Yngunza, K., Rodas-Simbron, K., \& Farro-Peña, G. (2013). Condiciones laborales y comportamientos en salud de los conductores de una empresa de transporte público del cono norte de Lima. Revista Enfermeria Herediana, 6(2), $107-114$.

Maslach, C., \& Jackson, S. (1986). Maslach Burnout Inventory Manual. Palo Alto: Consulting psychologists press.

Maslach, C., \& Jackson, S. (1993). The Maschach Burnout inventory. Palo Alto: California consulting press.

Ministerio de Transportes y Comunicaciones. (2012). Obtenido de http://www.mtc.gob.pe/portal/inicio.html 
Morales-Soto, N., Alfaro-Basso, D., \& Gálvez-Rivero, W. (2010). Aspectos psicosociales y accidentes en el transporte terrestre. Revista peruana de medicina experimental y salud pública, 27(2), 262-272.

Morris, C. G., \& Maisto, A. A. (2014). Psicología. (10 ed.). México: Pearson educación.

OMS. (2013). The Global Status Report on State Road Safety 2013. Ginebra: WHO Library Cataloguing-in.

Perry, G., Maloney, W., Fajnzylber, P., Mason, A., \& Saavedra-Chanduvi, J. (2007).

Informalidad: Escape y exclusión. Estudios del Banco Mundial Sobre América Latina (pág. 22). Washington D.C: VEGAP.

Pines, A., Aronson, E., \& Kafry, D. (1980). Burnout: from Tedium to Personal Growth. En M. Bosqued, Quemados El síndrome de Burnout Qué es y cómo superarlo (pág. 20). Barcelona: Ediciones Paidos Ibérica, S.A.

Policía Nacional del Perú. (2009). Estadísticas de colisiones viales en el Perú 1998-2006. Lima: PNP.

Price, D. M., \& Murphy, P. A. (1984). Staff Burnout in the perspective of grief theory. En P. R. Gil-Monte (Ed), El síndrome de quemarse por el trabajo: (Burnout): una enfermedad laboral en la sociedad del bienestar (págs. 110-111). Madrid: Ediciones Piramide.

Prieto, J. (2005). Desencadenantes del estrés laboral. Madrid: Ediciones Pirámide.

Ramos, I., Aldrete, M. G., Medina, S., \& León, S. G. (2013). Síndrome de Burnout y variables sociolaborales en trabajadopres de una unidad de atención primaria. Aportes interdisciplinarios en el ejercicio profesional de la salud mental, 2, pp 178-189. 
Salazar Concepción, S. I., \& Pereda De los Santos, E. C. (2010). Síndrome de Burnout y patrones de comportamiento ante tráfico en conductores. Psicol, 12, 141-169.

Toppinen-Tanner, S., Ojajärvi, A., Väänänen, A., Kalimo, R., \& Jäppinen, P. (2005). Burnout as a Predictor of Medically Cerified Sick-Leave Absences a Diagnosed Causes.

Behavioral Medicine, 31(1), 18-27.

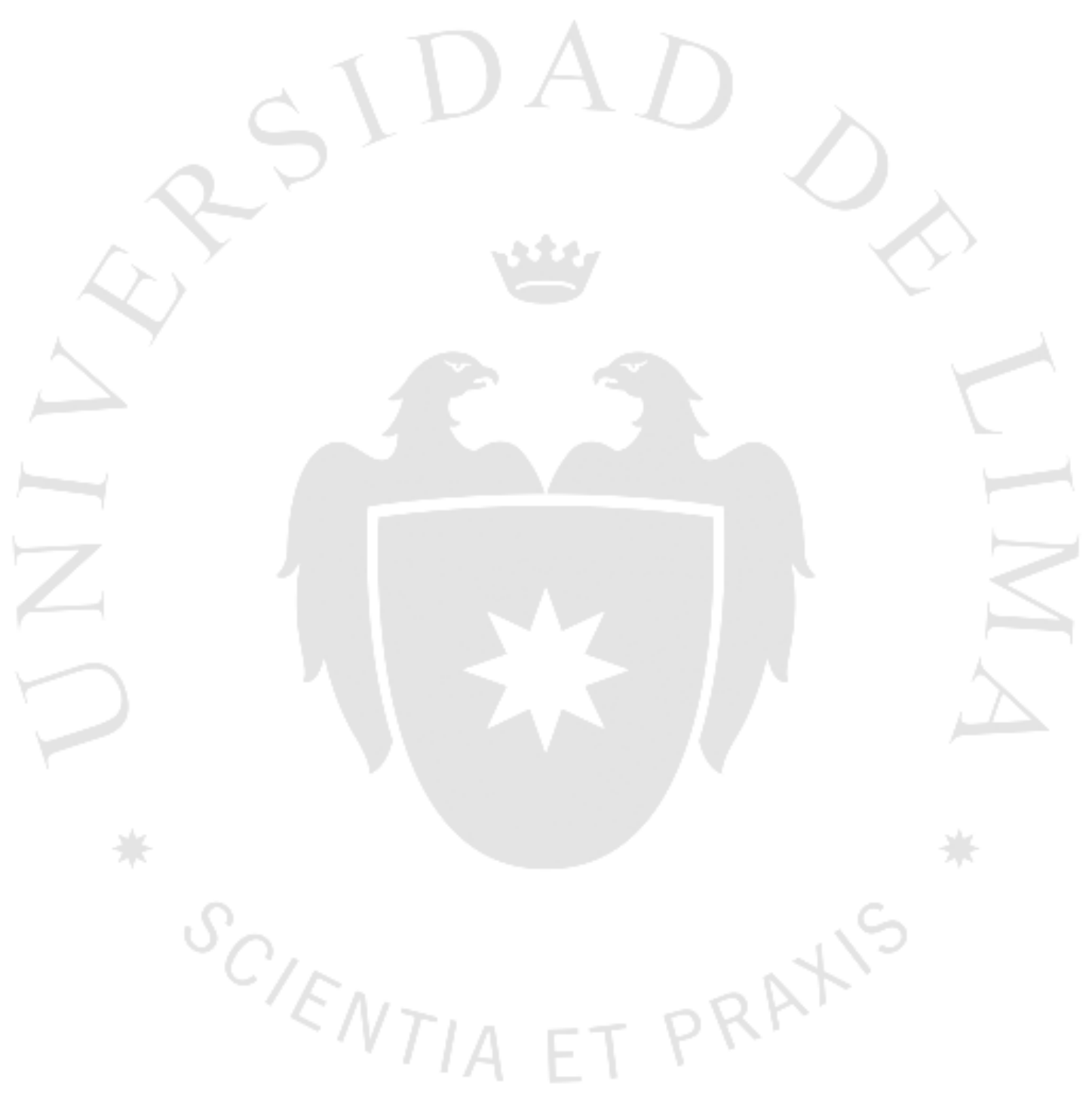


APÉNDICE A1

$\underline{\text { Baremo del Inventario Burnout de Maslach }}$

Baremo del Inventario burnout de Maslach (MBI)

\begin{tabular}{ccccc}
\hline Rango percentil & Agotamiento emocional & Despersonalización & Realización personal & Rango percentil \\
\hline 1 & 0 & & & 1 \\
5 & 2 & & 0 & 5 \\
10 & 5 & & 1 & 10 \\
15 & 6 & 0 & 2 & 15 \\
20 & 8 & & 3 & 20 \\
25 & 9 & & 4 & 25 \\
30 & 10 & 1 & 5 & 30 \\
35 & 11 & 2 & & 35 \\
40 & 12 & 3 & 6 & 40 \\
45 & 13 & & 7 & 45 \\
50 & 14 & 4 & 8 & 50 \\
55 & 15 & 5 & 9 & 55 \\
60 & 16 & 6 & 11 & 60 \\
65 & 17 & 7 & 12 & 65 \\
70 & 19 & 8 & 13 & 70 \\
75 & 20 & 9 & 14 & 75 \\
80 & 22 & 10 & 18 & 80 \\
85 & 27 & 11 & 20 & 85 \\
90 & 30 & 13 & 24 & 90 \\
95 & 36 & 20 & 44 & 95 \\
99 & 42 & 4,34 & 9,07 & M \\
M & 15,46 & 4,44 & 5,32 & D.E. \\
\hline D.E. & 6,63 & & & \\
\hline
\end{tabular}

Fuente: Inventario Burnout de Maslach (MBI), 1993. 
APÉNDICE A2

$\underline{\text { Prueba MBI }}$

\begin{tabular}{|c|c|c|c|c|c|c|c|c|c|c|c|c|c|c|c|c|c|c|c|c|c|c|}
\hline stبp & $\omega$ & $\omega$ & $\omega$ & $\oplus$ & & 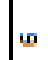 & $\omega$ & $\omega$ & 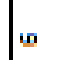 & $\omega$ & क & $\omega$ & 6 & 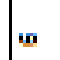 & 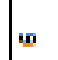 & $\omega$ & 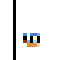 & $\omega$ & $\omega$ & $\omega$ & $\omega$ & \\
\hline 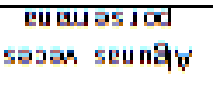 & $n$ & $n$ & $n$ & $n$ & $n$ & $n$ & $n$ & $n$ & $n$ & $n$ & $n$ & $n$ & $n$ & $n$ & $n$ & $n$ & $n$ & $n$ & $n$ & $n$ & $n$ & $n$ \\
\hline $\begin{array}{l}\text { Eu tan os Jod } \\
\text { zan eu }\end{array}$ & 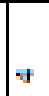 & 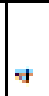 & 4 & 4 & 4 & 9 & 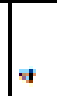 & 4 & ब & 4 & 8 & 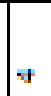 & 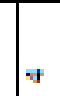 & \% & \% & o & 4 & 4 & \% & 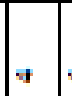 & 4 & 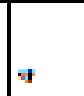 \\
\hline $\begin{array}{l}\text { cu je sosas } \\
\text { seunaty }\end{array}$ & $m$ & $m$ & $m$ & $m$ & $m$ & $m$ & $m$ & $m$ & $m$ & $m$ & $m$ & $m$ & $m$ & $m$ & $m$ & $m$ & $m$ & $m$ & $m$ & $m$ & $m$ & $m$ \\
\hline $\begin{array}{l}\text { sou au o saut } \\
\text { je zas eu }\end{array}$ & $n$ & rs & $\infty$ & $\sim$ & 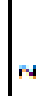 & 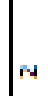 & $\mathrm{mu}$ & 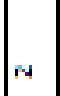 & 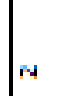 & 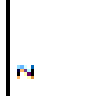 & 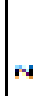 & 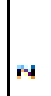 & $\sim$ & 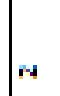 & N4 & 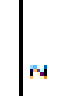 & $N$ & 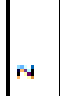 & 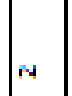 & 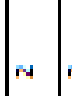 & 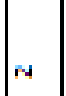 & 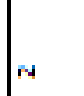 \\
\hline 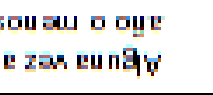 & 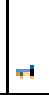 & - & F & न & F & - & -1 & -1 & -1 & F & F & Ft & - & -1 & -r & - & $\rightarrow$ & - & F & 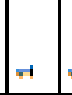 & F & F \\
\hline eכunn & 0 & 0 & 0 & o & o & o & 0 & o & o & 0 & 0 & o & 0 & 0 & 0 & 0 & 0 & 0 & 0 & 0 & 0 & 0 \\
\hline 를 & 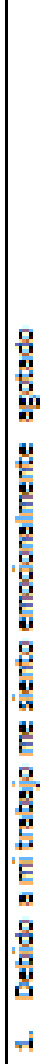 & 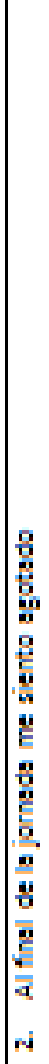 & 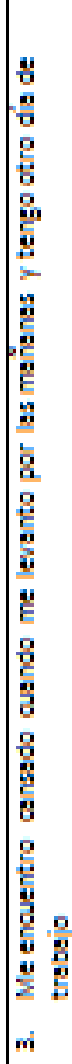 & 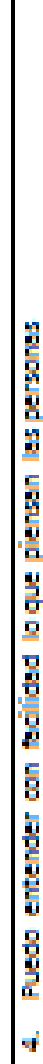 & 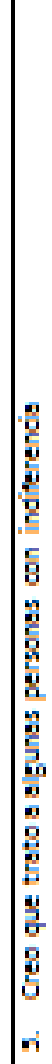 & 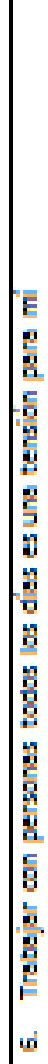 & 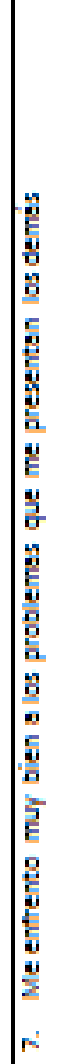 & 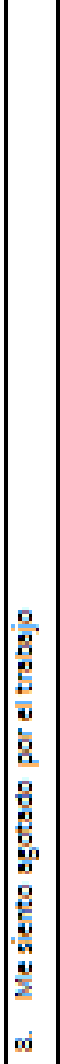 & 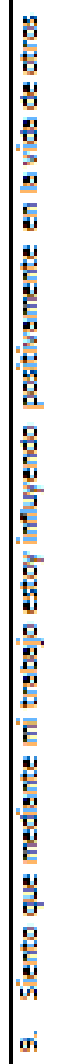 & 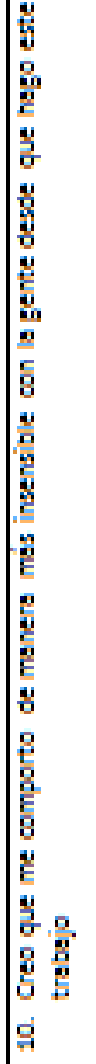 & 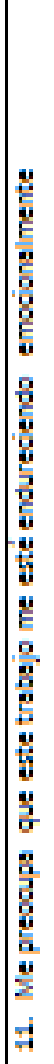 & 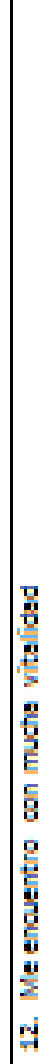 & 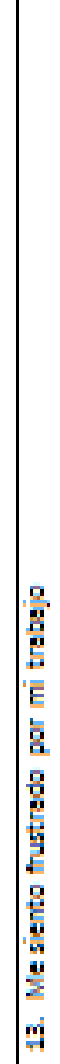 & 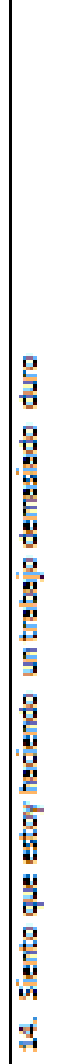 & 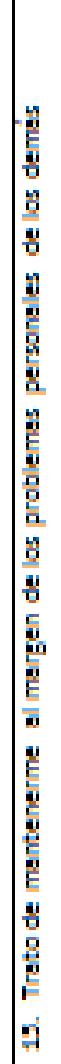 & 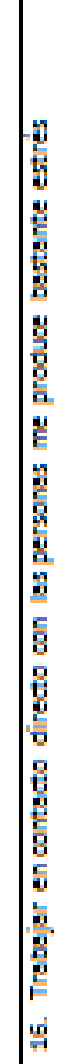 & 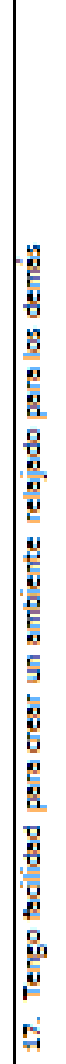 & 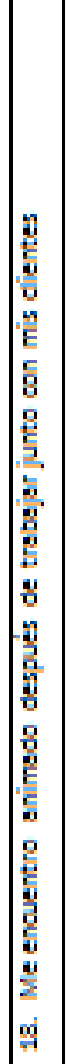 & 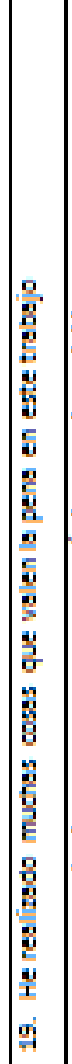 & 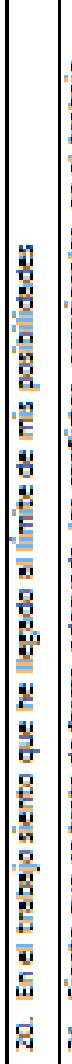 & 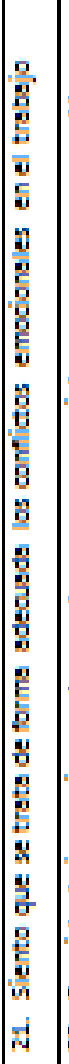 & 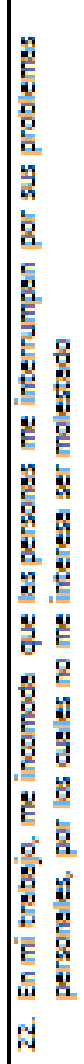 \\
\hline 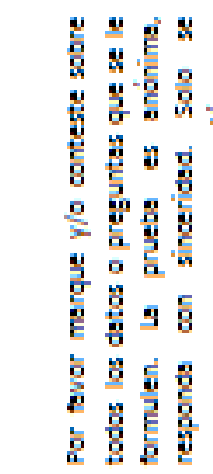 & & $\begin{array}{l}\frac{2}{3} \\
\frac{2}{2} \\
2\end{array}$ & 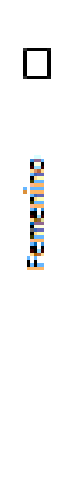 & & & & & 3 & 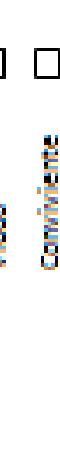 & 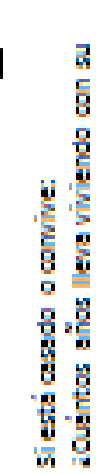 & & & 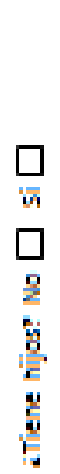 & 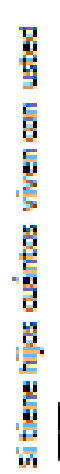 & & 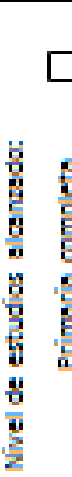 & 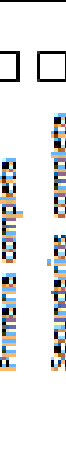 & 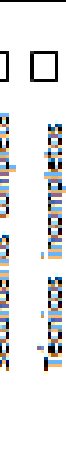 & 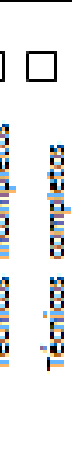 & 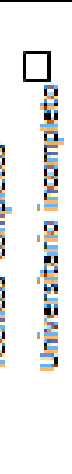 & 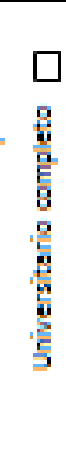 & 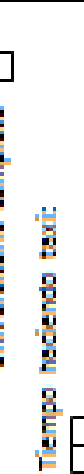 \\
\hline
\end{tabular}




\section{APÉNDICE A3}

\section{$\underline{\text { Permiso del autor de la validación de la prueba }}$}

De: MANUEL FERNANDEZ ARATA <mfernandeza1@usmp.pe>

Enviado: lunes, 22 de agosto de 2016 10:03 a.m.

Para: David Hurtado

Asunto: RE: Permiso para usar datos de investigación

Estimado David,

La información que encuentres en los distintos artículos que hemos publicado sobre el particular, además del libro "Realidad psicosocial del maestro de primaria", puedes utilizarla sin ningún inconveniente. Sólo tienes que colocar la referencia que corresponde. La versión que debes utilizar es el MBI-GS que es multiocupacional. Acompaño algunos artículos.

Saludos,

Manuel Fernández

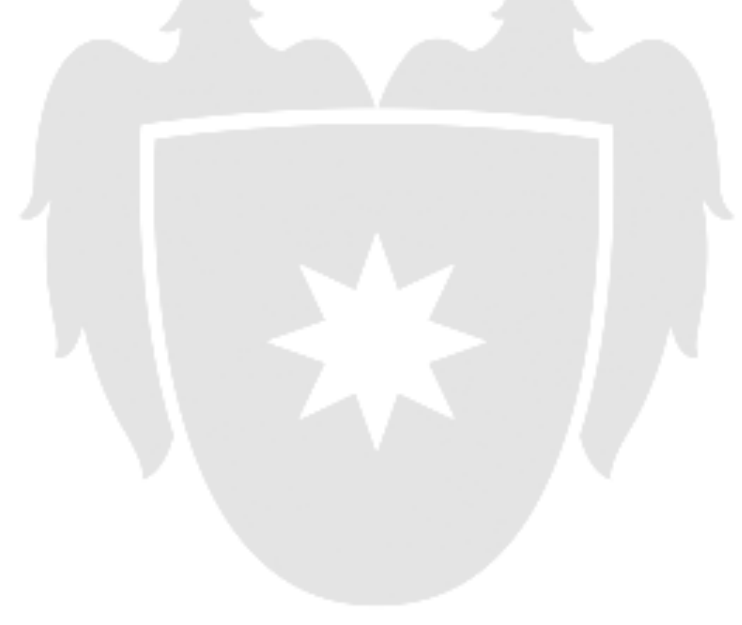


APÉNDICE B

$\underline{\text { Cronograma de Actividades }}$

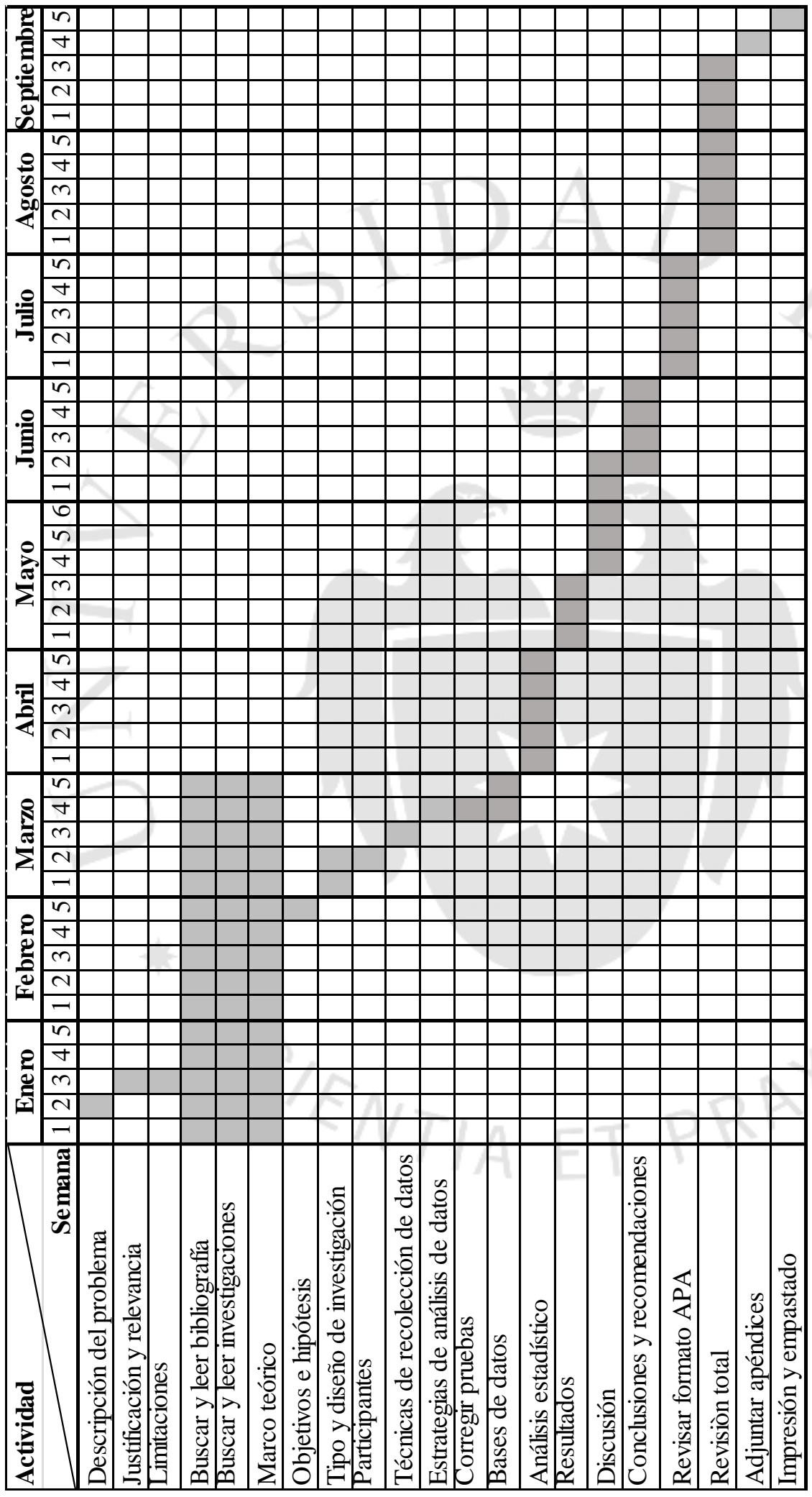

